\title{
The Effect of Consumption and Production Structure on Growth and Distribution. A Micro to Macro Model*
}

\author{
Tommaso Ciarli ${ }^{\dagger}$, André Lorentz $\ddagger$ Maria Savona, Marco Valente \\ Paper submitted to the Special Issue of Metroeconomica on 'The Institutional and Social Dynamics of \\ Growth and Distribution'
}

\begin{abstract}
The paper contributes to the literature on the relation between structural changes in demand and supply and growth. We develop a macro-economic model with agent-based micro-foundations that articulates the links between production and organisational structures on the supply side, and the endogenous evolution of income distribution on the demand side. The model contains a simplified, though robust, representation of individual firms in the final goods and capital sectors and classes of workers/consumers. The results, in addition to addressing the technical issue of the model's robustness, illustrate the micro- and mesoproperties of the simulated growth patterns. In particular, we observe and explain the interactions between technological change, firm organisation, income distribution, consumption behaviour and growth. The analysis performed on the simulated results broadly confirms and further extends the empirical evidence presented in the literature.
\end{abstract}

Keywords: Structural change; consumption; earnings distribution; growth

JEL: O12, J31, L23, D11, O41

*The paper benefited from comments and suggestions from G. Dosi, D. Fiaschi, L. Marengo, W. Semmler, G. White, U. Witt and participants in the International Conference on 'The Institutional and Social Dynamics of Growth and Distribution', Lucca, December 2007; the 16th International Input-Output Conference, July 2007; the 2nd Meeting of the Society for the Study of Economic Inequality (ECINEQ), July 2007; the 5th EMAEE Conference, May 2007. Part of the research was supported by DIME within the RAL-WP 3.3. Two anonymous referees provided very relevant contributions in the form of improvements to the paper. The usual disclaimers apply and any remaining errors are our own.

${ }^{\dagger}$ Evolutionary Economics Group, Max Planck Institute of Economics, Jena, Germany, ciarli@econ.mpg.de

${ }^{\ddagger}$ Evolutionary Economics Group, Max Planck Institute of Economics, Jena, Germany, lorentz@econ.mpg.de

${ }^{\S}$ University of Lille 1, France and SPRU, University of Sussex, UK, Maria.Savona@univ-lille1.fr

`University of L'Aquila and LEM Sant'Anna School for Advanced Studies, Pisa, Italy, valente@ec.univaq.it 


\section{Introduction}

Cross-country divergence in growth rates has been a solid empirical stylised fact for decades (Denison, 1967; Denison, 1979; Maddison, 1987; Barro, 1991; Durlauf and Quah, 1998). The theoretical and empirical assessment of the extent to which the (change in the) structure of the economy is one of its main determinants and, ultimately, is what determines changes in the production structure, (e.g. Saviotti and Gaffard, 2008) is a more debatable issue.

Since the seminal work by Pasinetti (1981), scholars in the Keynesian and Classical traditions have acknowledged that technological change, changes in the structure of production and the evolution of demand could disrupt the sectoral composition of the economy and the steady path of macroeconomic growth. This work is mainly in the context of aggregated models (see for instance Kurz and Salvadori, 1998; Cesaratto, Serrano, and Stirati, 2003).

Since the seminal contribution by Nelson and Winter (1982), the long-term impact of technical change on economic growth has become a rich and consolidated domain for analysis of evolutionary theory (Dosi, 1982; Dosi, Freeman, Nelson, Silverberg, and Soete, 1988; Chiaromonte and Dosi, 1993; Silverberg and Verspagen, 2005). However, within this stream of analysis, only a few scholars have attempted to look at the joint effect of supply changes and demand composition on growth and structural change from a sectoral and micro perspective (Verspagen, 1993; Verspagen, 2004; Montobbio, 2002; Lorentz, 2008; Lorentz and Savona, 2008; Ciarli and Valente, 2005; Ciarli, 2005). None of this work looks specifically at the interaction between structural changes in production and organisation, and changes in consumption. Saviotti and Pyka (2004) and Saviotti and Pyka (2008) examined economic growth as resulting from the emergence of new sectors and increased product variety. However, creation of variety is exogenous and links to the demand side are left unexplored.

In work investigating the role of the demand side, there have been a few major attempts to challenge standard neoclassical consumer theory and find evidence for some of the most heroic hypotheses on consumer behaviour (see for instance Deaton and Muellbauer, 1980b; Deaton and Muellbauer, 1980a; Cowan, Cowan, and Swann, 1997; Aversi, Dosi, Fagiolo, Meacci, and Olivetti, 1999). Demand constraints and is constrained by the response of supply at the micro-level of analysis. Changes in the structure of demand find their natural interlocutor and depend on whether and how firms respond to them, as Schumpeter emphasised (Schumpeter, 1934). Within the evolutionary literature, analysis of demand and consumption behaviour are still at an early stage, although a few recent contributions have looked at how consumption 'needs' evolve (Valente, 1999; Swann, 1999; Witt, 2001; Witt, 2006; Babutsidze, 2007), but have not taken account of the link between demand patterns and changes in the structure of production. Also, none of these contributions attempt explicitly to disentangle at micro-level the role of distributional changes as the natural channel for the evolution of consumption 'needs' into actual demand. 
The large and consolidated literature on the two-way link between economic growth and distributional change remains confined to macro-level analyses, since the seminal Kuznet's curve and the works by Pasinetti (1962), Meade (1963), Stiglitz (1969) and Tinbergen (1975), which were extended by (Atkinson, 1997; Galbraith, Lu, and Darity, 1999; Galbraith, 1999; Aghion, 2002). In the context of aggregate analysis, the extensive literature on skill biased technical change directly hints at a relation between demand and production structure. In line with Tinbergen (1975), wage dynamics and earnings distribution are argued to reproduce the competition between demand and supply of skills. The more recent empirical literature (for a review see Aghion, 2002), however, shows that earnings distribution is more complex than reproduction of education level distribution, with inequalities appearing also within educational classes. Galbraith, Lu, and Darity (1999) and Galbraith (1999) among others, proposed a different view of earnings distribution based on whether inequality in income and earnings, is due to the sectoral structure of a country. Wage distribution should ultimately depend on the specialisation of the economy, at both international (Prebish-Singer hypothesis) and national (à la Kaldor) levels.

At the micro-level of analysis, the literature on firm organisation offers an appealing explanation for the too simplistic skill-bias effect (Atkinson, 2007). Recently, Caroli and Van Reenen (2001) show that increased decentralisation of production and work organisation - for instance, due to the adoption of ICTs - demands greater responsibility and increased wage compensation for executives, but unchanged first-tier workers' wages. This literature implicitly reprises an overlooked stream of contributions from the 1960s and the 1970s (Simon, 1957; Lydall, 1959; Rosen, 1982), which demonstrate the relation between firms' organisational structure, the composition of workers and executives, and the corresponding wages structure. This work was extended, among others, by Waldman (1984), Abowd, Kramarz, and Margolis (1999), Prescott (2003) and some empirical contributions have produced corroborative results on the relation between firm size and wage distribution (Brown and Medoff, 1989; Oi and Idson, 1999; Criscuolo, 2000; Bottazzi and Grazzi, 2007).

Galbraith's position is to go beyond the rather bold, all-embracing explanation of technical change being responsible for skill-bias and wage polarisation. This explanation risks overlooking the complex set of 'side effects' that follow a firm's decision to adopt technology, which includes changes in the functional division of labour, organisational structure and wage stratification within the firm. In this respect, Simon and Lydall's contributions - and the micro-evidence provided since - offer a useful micro-level perspective of what goes on inside the firm alongside skill-biased technical change. It is at the intersection of this micro- and macro-level literature that our contribution is aimed.

Our conjecture, supported by various theoretical and empirical contributions and detailed in section 2, is that changes in economic structure and (trade and sectoral) specialisation have been accompanied by changes in the organisational structures of firms, which together have brought about changes in the wages and earning structures. Therefore, 
both micro- and meso-level mechanisms are behind the changes in consumption patterns, which feed back into changes in the production structure at firm and sectoral levels. Thus the original contribution of this work is along two axes:

First, on a theoretical level, we hope to contribute to the growth literature by explicitly introducing income distribution as one of the main channels of changes in the organisation of firms into consumption patterns. We suggest and model an explicit relation between organisation, technology and wage composition at firm-level, which goes beyond the wellknown skill bias effect in determining the distribution of income at macro-level. We also formalise a relation between changes in income distribution and changes in consumption, and, by endogenising the role of income distribution, we provide a valuable tool to extend the use of the model to policy simulations.

Second, from a methodological point of view, we provide a (agent-based) microfoundation for our conjecture and develop a model where micro-behaviour is directly inspired by the evolutionary literature. We include meso- and macro-level constraints feeding back into the micro-level, such that changes in the micro-level supply-side i.e. technological intensity, organisation and firm size - affect the composition of workers/income classes and, in turn, consumption behaviour. Demand affects firm size and shapes the market structure. This leads to the emergence of different patterns of growth and income distribution which ultimately become new constraints at the micro-level of decision making. The purpose of the model is to produce simulated results fitting the existing empirical evidence and (possibly, more relevantly) to root the simulation's equivalents of macro-phenomena onto their underpinning micro-components, by showing how they are generated.

The paper introduces a general micro to macro framework and provides a detailed description of the model, its rationale and hypotheses. For reasons of space, we focus on the analysis of the main aggregate properties of the model, and identify the most relevant micro-dynamics behind them.

The paper is organised as follows. Section 2 describes the model, the rationale and the underlining assumptions in detail. Section 3 provides an analysis of its properties via numerical simulations; Section 3.2 reports the results of the micro-meso dynamics and Section 3.3 the macro-dynamics of growth and income distribution. Finally, Section 4 summarises the main findings and proposes directions for future research where extensions of this model might be usefully exploited.

\section{The Model}

We model an unconstrained economy where population grows endogenously as a response to labour demand. Following existing Schumpeterian growth models (see, among others Chiaromonte and Dosi, 1993; Silverberg and Verspagen, 2005), the economy is composed of two sectors - manufacturing and capital - and different classes of consumers. We assume that firms in the manufacturing sector can freely borrow on the financial market. 
Nonetheless, a short term, partially endogenous, constraint is determined by the production capacity of capital firms, which supply the manufacturing firms. These rather bold assumptions allow us to emphasise the role of the structural variables over population growth rate and labour market dynamics. The main features of the model are described below.

First, firms produce a good with different quality levels of the same characteristic, which represent competing technologies/designs. This allows us to define product varieties within a sector or to define structural differences in terms of different sectors, which satisfy different consumer needs, without having to define economic sectors. Here, we are not dealing with the evolution of a good; we want to analyse the effect of a heterogenous composition of consumption, in which firms can better address one or another class of consumer preferences. We do not model the strategic behaviour of firms with respect to a possible trade-off between quality and price; we are interested in analysing how the changing composition of demand (classes) — an outcome of firm organisation determines growth and distributional patterns through firm selection.

Second, firms are defined with respect to their organisation structure in terms of both number of hierarchical tiers of workers and executives, and wage differentials across tiers. As already mentioned, organisational structure has been found to be a an important aspect of income distribution, but is often overlooked in the growth-distribution literature. We determine a 'national' minimum wage at macro level. This is the result of (un)employment dynamics, and of the bargaining that takes place when consumer prices and the average contribution of labour change.

Third, the hierarchical structure of wages, linked to the organisation, determines the distribution of earnings and income. The aim is to analyse the relation between changes in the organisation of production and changes in the demand side. The different tiers of the firm are reflected in corresponding classes of consumption.

Fourth, having defined consumer classes, consumption behaviour draws upon the theoretical construction developed by Valente (1999). The composition of each class is defined in terms of consumption 'needs' and preferences. The distribution of consumer preferences over the characteristics of goods defines the demand curve and the firms' production shares.

Finally, technological change affects the production of capital and its use by manufacturing firms. Changes in production processes are modelled as investment in different capital vintages. By changing vintages, firms alter the capital/labour ratio of their technology, which affects the composition of the labour structure and income distribution in the consumer market. An increase in productivity from a new vintages is linked to the ability of capital firms to invest in research and development (R\&D).

\subsection{Final Good Firms}

We model a given population of $f \in\{1,2, \ldots, F\}$ firms in the manufacturing sector. Each firm produces one good, defined by a set of characteristics and price, and faces a related 
share of demand.

\subsubsection{Production process and sales}

We assume that the level of demand received by a firm is met from current production and inventories, or delayed at no cost. The delayed orders increase the existing backlog of unfulfilled demand. Decisions about the quantity to produce are meant to smooth out short term volatility, and are aimed at an amount of output that, on average, will be sufficient to meet expected demand with no backlogs, and to maintain a precautionary level of inventory.

Current expected sales are a convex combination of past expectations $\left(Y_{t-1}^{e}\right)$ and share of total demand faced by a firm $\left(Y_{t-1}\right):^{1}$

$$
Y_{t}^{e}=a^{s} Y_{t-1}^{e}+\left(1-a^{s}\right) Y_{t-1}
$$

We assume a slow adaptation in sales expectations $\left(a^{s}\right)$ as an outcome of agents' conservative behaviour aimed at smoothing out short term volatility. In order to cover unexpected changes in demand, firms maintain a desired level of inventories $\left(\bar{s} Y_{t}^{e}\right)$, where $\bar{s}$ is a fixed ratio. $^{2}$

Desired production $\left(Q_{t}^{d}\right)$ therefore depends on: expected demand $\left(Y_{t}^{e}\right)$, available inventories $\left((1+\bar{s}) Y_{t}^{e}-S_{t-1}\right)$ and unfulfilled demand from the previous simulation steps, the backlog, $B_{t-1}$ :

$$
Q_{t}^{d}=\max \left\{(1+\bar{s}) Y_{t}^{e}-S_{t-1}+B_{t-1} ; 0\right\}
$$

Actual output produced $\left(Q_{t}\right)$ may not reach the desired level because of limitations in capital or labour availability:

$$
Q_{t}=\min \left\{Q_{t}^{d} ; A_{t-1} L_{t-1}^{1} ; D K_{t-1}\right\}
$$

$A_{t-1}$ is the level of productivity of labour $\left(L_{t-1}\right)$ embodied in the firms' capital stock $\left(K_{t-1}\right)$ and $D K_{t-1}$ is the maximum production level allowed by this capital stock. The capital intensity $\left(\frac{1}{D}\right)$ remains fixed ${ }^{3}$.

Then, the gap between actual demand and production is reflected in the inventories or, if these are null and sales exceed production, in the backlog, computed as follows:

$$
\begin{array}{r}
S_{t}=\max \left\{S_{t-1}+Q_{t}-Y_{t}-B_{t-1} ; 0\right\} \\
B_{t}=-\min \left\{S_{t-1}+Q_{t}-Y_{t}-B_{t-1} ; 0\right\}
\end{array}
$$

\footnotetext{
${ }^{1}$ We suppress the firm index to improve readability. It is implicit that each equation is replicated for each firm, and we refer to the definition of parameter values to identify differences across firms.

${ }^{2}$ We assume an inventory/sales ratio that corresponds to the lower empirically observed values (see, e.g. McCarthy and Zakrajšek, 2000; U.S. Census Bureau, 2008), to avoid level effects that may be linked to the accumulation of inventories, and to reduce the propagation of production fluctuations.

${ }^{3}$ This assumption is sustained by evidence from numerous empirical studies, starting with Kaldor (1957). The capital investment decision in section 2.2.3 ensures that the actual capital intensity remains fixed over time.
} 


\subsubsection{Labour}

We draw upon Simon (1957), Lydall (1959), Rosen (1981) and Rosen (1982) and further extensions (Waldman, 1984; Abowd, Kramarz, and Margolis, 1999; Prescott, 2003) to represent the firm's labour organisation. According to this literature, the size of the firm and the number of its hierarchical tiers - i.e. the proportions of executives and workers - affect the structure of pay.

Given the level of output, firms employ (displace) first tier workers $\left(L_{t}^{1}\right)$ according to the labour productivity of the capital vintages $\left(A_{t-1}\right)$, and in order to maintain an unused labour capacity $\left(u^{l}\right)$ to insure against unexpected labour shortages:

$$
L_{t}^{1}=\epsilon_{L} L_{t-1}^{1}+\left(1-\epsilon_{L}\right)\left[\left(1+u^{l}\right) \frac{1}{A_{t-1}} \min \left\{Q_{t}^{d} ; D K_{t-1}\right\}\right]
$$

where the inertial factor $\epsilon_{L}$ mimics labour market rigidities, and is interpreted as the elasticity in matching models (see Equation 34). We assume there is quite a low adaptation in labour markets (large $\epsilon_{L}$ and $\epsilon_{M}$ ).

In addition to first tier employees, firms need to hire 'executives' to manage every batch of $\nu$ first tier workers, third level executives for every group of $\nu$ second tier workers, and so on. The number of workers in each tier, given $L_{t}^{1}$ is thus

$$
\begin{aligned}
L_{t}^{2}= & L_{t}^{1} \nu^{-1} \\
L_{t}^{3}= & L_{t}^{1} \nu^{-2} \\
& \vdots \\
L_{t}^{\Lambda}= & L_{t}^{1} \nu^{1-\Lambda}
\end{aligned}
$$

where $\Lambda$ is the total number of tiers required to manage the firm. Consequently, the total number of workers is

$$
L_{t}=L_{t}^{1}+L_{t}^{2}+\ldots+L^{\Lambda}=\sum_{l=1}^{\Lambda} L_{t}^{l}
$$

Ultimately, the constraint on production due to labour is determined by first tier workers and their productivity only. The 'managers', required to organise production, increase the variable costs. We implicitly assume that a firm finds its best organisational configuration given the number of first tier workers, and given the organisational design proxied by $\nu$.

\subsubsection{Wage, cost and price determination}

The labour cost essentially depends on the minimum wage, endogenously determined at macro level (see Section 2.3), and on the firm's hierarchical structure. First tier wages are set by firms as a fixed multiple $\omega$ of the minimum wage $w_{t-1}^{m}$ :

$$
w_{t}^{1}=\omega w_{t-1}^{m}
$$

As we move upstream in the organisational hierarchy, the wage increases by a fixed tier multiplier $b$, which determines the skewness in the wage distribution, in line with Simon 
(1957) and Lydall (1959).

$$
\begin{gathered}
w_{t}^{2}=b w_{t}^{1} \\
w_{t}^{3}=b w_{t}^{2}=b^{2} w_{t}^{1} \\
\vdots \\
w_{t}^{\Lambda}=b^{\Lambda-1} w_{t}^{1} .
\end{gathered}
$$

As noted in Atkinson (2007), the exponential structure of wage-tier increase is not sufficient to explain the skewness in earnings distribution. On top of their wages, executives can receive wage premiums, $\psi_{t}^{l}$. Firms distribute (to managers only) the profits available after paying for capital purchases, $R_{t}^{D}$. The premium paid to for each manager is proportional to the regular wage:

$$
\psi_{t}^{l}=\left\{\begin{array}{l}
\frac{w_{t}^{l}}{\sum_{l=2}^{\Lambda} w_{t}^{l}} R_{t}^{D} ; \forall l \in\{2 ; \Lambda\} \\
0 ; \text { for } l=1
\end{array}\right.
$$

Therefore, the overall earnings for a member of tier $l$ is $w_{t}^{l}+\psi_{t}^{l}$, with $\psi_{t}^{1}=0$.

The price is set at firm level as a mark-up on variable costs. ${ }^{4}$

$$
p_{t}=(1+\mu) \frac{1}{A_{t-1}} \sum_{l=1}^{\Lambda} w_{t}^{l} \frac{L_{t-1}^{l}}{L_{t-1}}
$$

Note that the tier-wage structure of variable costs implies diseconomies of scale in labour input based on the evidence that labour costs are higher for larger firms (Idson and Oi, 1999; Criscuolo, 2000; Bottazzi and Grazzi, 2007). This is due to the necessary increase in the number of tiers of managers required to co-ordinate a larger number of first tier workers. Profits $\left(\pi_{t}\right)$ then result as the difference between the value of current sales $\left(Y_{t}\right)$ and the variable costs of production:

$$
\pi_{t}=p_{t-1} Y_{t}-\sum_{l=1}^{\Lambda} w_{t}^{l} L_{t}^{l}
$$

We assume that when facing capital constraint, firms always prioritise capital investment, and whenever there is a positive residual, this is distributed to managers. Distributed profits hence amount to:

$$
R_{t}^{D}=\max \left\{0 ; \sum_{\tau=1}^{t} \pi_{\tau}-\sum_{\tau_{h}=1}^{t} k_{\tau_{h}}^{e} p_{g, \tau_{h}}^{K}-\sum_{\tau=1}^{t-1} R_{\tau}^{D}\right\}
$$

where $k_{\tau_{h}}^{e}$ is the capital investment of vintage $\tau_{h}$ and $p_{g, \tau_{h}}^{K}$ its price set by the capital firm $g$ from which it is acquired (see respectively Sections 2.1.4 and 2.2.2).

\footnotetext{
${ }^{4}$ A common assumption in evolutionary models, supported by empirical evidence that dates back to Hall and Hitch (1939), and more recently to Blinder (1991) and Hall, Walsh, and Yates (1997).
} 


\subsubsection{Capital and investment}

Following Amendola and Gaffard (1998) and Llerena and Lorentz (2004), capital goods are not used as production inputs in the strict sense, but constitute the basis for the firm's production capacity. The accumulation of capital is a pre-condition for any production activity, constraining the actual production level and affecting the efficiency of the labour force. This is also in line with some neo-Schumpeterian models (Verspagen, 1993; Llerena and Lorentz, 2004) which provide micro-foundations for the Kaldor-Verdoorn cumulative causation mechanism (Kaldor, 1957; Verdoorn, 1949). Therefore, in our model, firms' investment decisions depend on comparisons between current maximum production capacities and expected demand, plus a desirable stock of unused capital capacity to face short term demand changes. We assume that capital intensity is constant for all capital vintages and all capital producers; thus, we can measure capital stock in terms of the amount of final product a unit of capital can generate (capital capacity). We also assume that firms can freely access a financial market for capital investment, and we remove profit constraints on the level of investment. As a consequence, following a sharp increase in demand, firms may well register short term negative profits, and require a few time periods before they are again able to distribute profits. This is not to say that Modigliani and Miller (1958) theory is correct, no are we denying that the financial structure influences the investment strategy (e.g. Fazzari, Hubbard, and Petersen, 1988). However, we prefer to study the model behaviour without constraints that might determine the output and obscure the effect of the variables that characterise changes in the structure of production and demand.

The capital stock of a firm, where $V$ indicates the number of capital vintages acquired, $k_{h}$ and $\tau_{h}$ the amount of capital and date of purchase of vintage $h$ respectively, is computed as:

$$
K_{t}=\sum_{h=1}^{V} k_{h}(1-\delta)^{t-\tau_{h}}
$$

where $\delta$ is the depreciation rate. The level of productivity embodied in the capital stock is computed as the average productivity across all the vintages available:

$$
A_{t}=\sum_{h=1}^{V} \frac{k_{h}(1-\delta)^{t-\tau_{h}}}{K_{t}} a_{\tau_{h}}
$$

where $a_{\tau_{h}}$ is the productivity embodied in the $h$ vintage.

Indicating as $u$ the required percentage of unused stock, then the desired amount of new capital (expressed in production units) is:

$$
k_{t}^{e}=\max \left\{0 ;(1+u) \frac{Y_{t}^{e}}{D}-K_{t-1}\right\}
$$

If $k_{t}^{e}$ is positive, the firm needs to select one of the capital producers $g \in\{1,2, \ldots, G\}$ and place an order for the desired stock. To select among capital producers we built an index proportional to the productivity of the producers' vintages $a_{g, t-1}$, and to the inverse 
of the capital price $p_{g, t-1}^{K}$ and time of delivery $r_{g, t}$ :

$$
I_{g}=\left(\frac{p_{g, t-1}^{K}}{1+\bar{p}_{t-1}^{K}}\right)^{-\theta_{f}^{p}} \cdot\left(\frac{a_{g, t-1}}{1+\bar{a}_{t-1}}\right)^{\theta_{f}^{a}} \cdot\left(\frac{r_{g, t}}{1+\bar{r}_{t}}\right)^{-\theta_{f}^{d}}
$$

where over-signed variables are the non-weighted averages across capital producing firms, and $\theta_{f}^{p}, \theta_{f}^{a}, \theta_{f}^{d}$ are the manufacturing firm's $f$ constant preferences over capital price, productivity and delivery time. After computing the indexes for all capital producers, manufacturing firms select the producer with the highest normalised index $\hat{I}_{g}=\frac{I_{g}}{\sum_{g=1}^{G} I_{g}}$.

The price of the capital good and the productivity embodied, are fixed at the time of the order. However, actual delivery may take place after one or more time steps, depending on the production capacity of the supplier $\left(Q_{t}^{K}\right)$ and its existing order book $\left(K_{t}^{D}\right)$ (see next Section 2.2.1). That is, an investment in new capital $k_{\hat{f}, t}^{e}$, bought from capital firm $g$, increases the capital stock of the manufacturing firm $\hat{f}$ in period $t+1$ only if $Q_{g, t}^{K} \geq U_{g, t-1}^{K}+\sum_{f=1}^{\hat{f}} k_{g, \tau_{t, f}}$. While a manufacturing firm is waiting for an ordered capital, it cannot submit new orders, or revise existing ones.

This feature of investment dynamics has three important implications. First, it is in line with the micro level empirical evidence on the lumpiness of investment (e.g Doms and Dunne, 1998). Second, it generates a trade-off between immediately acquiring a less productive vintage and waiting longer for a more productive vintage. This also smooths the cumulative mechanism that increases the probability of first investors being more and more productive with respect to competitors. Third, capital realisation places a temporary constraint on economic growth which is not imposed, but depends on the accumulation of production capacity in the capital sector.

\subsection{Capital sector}

Capital goods are produced by firms $g \in\{1,2, \ldots, G\}$ belonging to the capital sector. Each capital good is characterised by its vintage $\tau_{h}$ and embodied productivity level $a_{\tau_{h}}$. Machinery firms receive commissions from manufacturing firms, and use their production capacity to fulfil them, in order of receipt. For simplicity, we assume that machinery firms employ labour as the unique input; the introduction of capital input would require a quite complicated intrasectoral input-output relations model, which would have the only effect of changing the scale of our results (by requiring more firms, labour, and so on). The commissions determine firm level demand in the capital sector. In line with the empirical evidence (see for instance Doms and Dunne, 1998; Cooper and Haltiwanger, 2006), we assume that the production of capital is just-in-time, with no expectation formation or accumulation of inventories of unsold capital. Firms in the capital sector may increase the productivity of the produced capital investing in $R \& D$, via the hiring of new engineers.

\subsubsection{Production process of capital goods}

Capital goods firms have order books of orders $k_{\tau_{j, f}}$, where the $\tau_{j, f}$ refers to the date that the order $k_{f}^{e}$ was received from manufacturing firm $f$. A capital firm's demand in period 
$t$ then is the sum of current orders and the backlog of orders received in previous periods that have not been fulfilled $\left(U_{t-1}^{K}\right)$ :

$$
K_{t}^{D}=\sum_{f=1}^{F} k_{\tau_{t, f}}+U_{t-1}^{K}
$$

The production function of capital firms is

$$
Q_{t}^{K}=A^{K} L_{t-1}^{K_{1}}
$$

where $L_{t-1}^{K_{1}}$ is the number of first tier workers in the capital goods' firms and $A^{K}$ is the labour productivity, assumed to be constant in this sector. In each period firms sell the available manufactured orders

$$
Y_{t}^{K}=\min \left\{Q_{t}^{K} ; K_{t}^{D}\right\}
$$

and over time cumulate a number of uncovered orders

$$
U_{t}^{K}=\sum_{i=1}^{t} K_{i}^{D}-\sum_{j=1}^{t} Y_{j}^{K}
$$

assuming that $U_{0}^{K}=0$. When the production capacity $Q_{t}^{K}$ is smaller than the total order book $K_{t}^{D}$ capital firms complete the oldest orders first, followed by the next most recent ones, recording the completed share of the oldest, unfinished order, which will be the first to be completed in the next step.

The number of first tier workers slowly adapts to changes in demand, in order to smooth out short-term volatility. That is, capital firms modify their labour force in an attempt to fulfil all existing orders and maintain a percentage of extra-capacity $u^{K}$ :

$$
L_{t}^{K_{1}}=\epsilon_{M} L_{t-1}^{K_{1}}+\left(1-\epsilon_{M}\right)\left[\left(1+u^{K}\right) \frac{K_{t}^{D}}{A^{K}}\right]
$$

$\epsilon_{M}$ is the speed of adjustment of labour in the capital sector. In terms of the manufacturing sector, total employment results from the sum of the different tiers, which are generated according to the same coefficient: one worker to coordinate every $\nu$ workers in a lower tier. The total number of workers in a firm in the capital sector is therefore:

$$
L_{t}^{K}=L_{t}^{K_{1}}+L_{t}^{K_{2}}+\ldots+L_{t}^{K_{\Lambda}}=L_{t}^{K_{1}} \sum_{K_{l}=1}^{K_{\Lambda}} \nu^{1-K_{l}}
$$

\subsubsection{Wage, costs and price determination}

Symmetric to the manufacturing sector, prices of capital goods $\left(p_{t}^{K}\right)$ are set according to a mark-up rule $\left(\mu^{K}\right)$. In the case of machinery firms, the variable costs include the total labour costs (workers, executives and engineers) divided by the level of production $\left(Q_{t}^{K}\right)$ :

$$
p_{t}^{K}=\left(1+\mu^{K}\right)\left(\frac{\sum_{K_{l}=1}^{K_{\Lambda}} w_{t}^{K_{l}} L_{t-1}^{K_{l}}+w_{t}^{E} L_{t-1}^{E}}{Q_{t}^{K}}\right)
$$


where $w^{K_{l}}$ and $w^{E}$ are the wages of workers and engineers respectively, and $L_{t}^{E}$ is the number of engineers.

First tier capital workers' and engineers' wages are also defined as a multiple of the minimum wage $\left(\omega^{K}\right.$ and $\omega^{E}$ respectively):

$$
\begin{gathered}
w_{t}^{K_{1}}=\omega^{K} w_{t-1}^{m} \\
w_{t}^{K_{2}}=b w_{t}^{K_{1}} \\
\vdots \\
w_{t}^{K_{\Lambda}}=b^{K_{\Lambda}-1} w_{t}^{K_{1}} \\
w_{t}^{E}=\omega^{E} w_{t-1}^{m}
\end{gathered}
$$

while the same hierarchical wage structure for manufacturing workers applies to upstream tiers in the capital sector (Equation 10). Due to lack of evidence on the organisation of engineers' work, we assume they work independently within the same tiers. Given the very low numbers of engineers, this assumption does not affect the results.

The profits $\pi_{t}^{K}$ are then computed as the difference between the value of sales and the costs for workers and engineers:

$$
\pi_{t}^{K}=p_{t}^{K} Y_{t}^{K}-\sum_{K_{l}=1}^{K_{\Lambda}} w_{t}^{K_{l}} L_{t-1}^{K_{l}}-w_{t}^{E} L_{t-1}^{E}
$$

These profits are cumulated $\left(\Pi_{t}^{K}\right)$ by machinery firms and used to finance their R\&D activity or are redistributed to executives via premiums ${ }^{5}$. The share of redistributed profits is computed as follows:

$$
R_{t}^{K}=\max \left\{0 ;(1-\rho) \Pi_{t}^{K}\right\}
$$

with

$$
\Pi_{t}^{K}=\sum_{\tau=1}^{t-1} \pi_{\tau}^{K}-\sum_{\tau=1}^{t-1} w_{\tau}^{E} L_{\tau}^{E}-\sum_{\tau=1}^{t-1} R_{\tau}^{K}
$$

As described in the next section, $\mathrm{R} \& \mathrm{D}$ investments include hiring new engineers to perform the R\&D activity.

\subsubsection{R\&D and Innovation in Machinery Firms}

Given the amount of resources devoted to hiring researchers, R\&D is aimed at improving the characteristics of a capital good and ultimately maintaining or increasing the machinery firm's market share. The outcome of R\&D activity is stochastic, though the probability of obtaining an increase in productivity $\left(p^{i n n}\right)$ depends on the amount of financial resources devoted to it and, therefore, to the number of engineers employed $\left(L_{t-1}^{E}\right)$. This is in line with Nelson and Winter (1982) and the most of the evolutionary models developed since, and follows the scheme presented in Llerena and Lorentz (2004).

$$
p_{t}^{i n n}=1-e^{-\zeta L_{t-1}^{E}}
$$

\footnotetext{
${ }^{5}$ The scheme of distribution of premiums is the same as for final good firms.
} 
Firms define the number of engineers they wish to employ as a ratio $\nu^{K}$ of first tier workers, constrained by the share $\rho$ of cumulated profits they allocate to R\&D:

$$
L_{t}^{E}=\min \left\{\nu^{K} L_{t}^{K} ; \max \left\{\frac{\rho \Pi_{t}^{K}}{w_{t}^{E}} ; 0\right\}\right\}
$$

If the R\&D activity is successful, the characteristics of the newly developed capital vintage are themselves randomly defined, and depend on the outcome of past $\mathrm{R} \& \mathrm{D}$ efforts. The $R \& D$ routine follows a stochastic process of the form:

1. Firms draw a number from a Uniform distribution on $[0 ; 1]$.

2. If this number is contained in the interval $\left[0 ; p_{t}^{i n n}\right]$, the $\mathrm{R} \& \mathrm{D}$ is successful.

3. If the $R \& D$ is successful, the characteristics of the newly developed vintage are randomly drawn as follows

$$
a_{\tau_{h}}=a_{\tau_{h-1}}\left(1+\max \left\{\varepsilon_{t}^{a} ; 0\right\}\right)
$$

where $\varepsilon_{t}^{a} \sim N\left(0 ; \sigma^{a}\right)$ is a normally distributed random function.

\subsection{Minimum wage}

The minimum wage $\left(w^{m}\right)$ is negotiated at the macro-economic level and defines the lowest bound of firms' wage setting ${ }^{6}$. We assume the negotiation to be linked to three main macroeconomic dynamics: (i) labour productivity growth, to maintain pace with the labour value contribution; (ii) consumer prices, to maintain purchasing power over the long run; and (iii) unemployment, due, for example, to efficiency wages, corporatism, or bargaining. This boils down to an outward shifting 'wage curve', which has been well established by empirical evidence (Blanchflower and Oswald, 2006; Nijkamp and Poot, 2005). The shift component is due to full re-negotiation when the increase in both average price $(\bar{P})$ and aggregate productivity $(\overline{A a})$ - with respect to the previous negotiation in $t_{0}$ - exceeds a boundary ratio (respectively $\Omega^{P}$ and $\left.\Omega^{A}\right):^{7}$

$$
\triangle w_{t}^{m}= \begin{cases}-\epsilon^{U} \triangle \overline{U m}_{t} & \text { If } \overline{A a}_{t} \leq \overline{A a}_{t_{0}} \Omega^{A} \text { or } \bar{P}_{t} \leq \bar{P}_{t_{0}} \Omega^{P} \\ -\epsilon^{U} \triangle \overline{U m}_{t}+\epsilon^{A} \triangle \overline{A a}_{t}+\epsilon^{P} \triangle \bar{P}_{t} & \text { If } \overline{A a}_{t}>\overline{A a}_{t_{0}} \Omega^{A} \& \bar{P}_{t}>\bar{P}_{t_{0}} \Omega^{P}\end{cases}
$$

where $\triangle \overline{U m}_{t}=\frac{\overline{U m}_{t}}{\overline{U m}_{t-1}}-1$ is unemployment growth and $\triangle \overline{A a}_{t}$ and $\triangle \bar{P}_{t}$ are growth in labour productivity and consumer prices respectively. The $\epsilon \in(0,1)$ are the corresponding elasticities of the minimum wage with respect to change in the three macro dynamics.

\footnotetext{
${ }^{6}$ We are aware that heterogeneous occurrences in the income distribution across countries are partly due to institutional differences in the minimum wage settings (e.g. Gottschalk and Smeeding, 1997; Cornia, 2003), and to the existence of an informal economy (e.g. Cornia, 2003). The present version of the model would allows us to study the joint role of minimum wage on income inequality, analysing the wage setting parameters that we assume in this paper. This is left for future studies.

${ }^{7}$ Changes in productivity $(\overline{A a})$ and consumer prices $(\bar{P})$ are computed as moving averages of the type $\bar{X}_{t}=d X_{t-1}+(1-d) \bar{X}_{t-1}$. We thus consider that the bargaining bodies evaluate variable trends and overlook short cyclical changes - smoothing adapting expectations - and that they perceive recent changes as more relevant (assuming a small value for $d$ ).
} 
We use robust empirical estimates for $\epsilon^{U}$ (Blanchflower and Oswald, 2006; Nijkamp and Poot, 2005), an equal value for $\epsilon^{A}$ and assume a $50 \%$ indexation of wages to price changes $\left(\epsilon^{P}\right)$.

Finally, given our earlier assumption of unconstrained labour resources, we need to derive unemployment rates based on labour hiring. We use the well established Beveridge Curves, which show a negative relation between the rate of vacancies - endogenously determined in the model at micro level - and the rate of unemployment. We assume that the labour market can be represented by a matching model (Petrongolo and Pissarides, 2001; Yashiv, 2007), and we use a hyperbolic form of the matching function ${ }^{8}$ :

$$
U m_{t}=C^{H}+\beta / \bar{V}_{t-1}
$$

where $C^{H}$ is the constant and $\beta$ defines the relation between vacancies $V_{t-1}$ and unemployment $\left(\bar{V}_{t-1}\right.$ refers to the moving average, as defined in footnote 7$)$. Both parameters are set taking account of the mixed empirical evidence from the few available estimates (Wall and Zoega, 2002; Nickell, Nunziata, Ochel, and Quintini, 2002; Teo, Thangavelu, and Quah, 2004). A mean value of these estimates is found in Fagiolo, Dosi, and Gabriele (2004), who show that fully random matching models fail to reproduce Beveridge curves, and require the assumption of path dependency in labour supply and demand.

To close the minimum wage setting, we define the number of vacancies $V_{t-1}$ as the sum of vacancies in all sectors of the economy: final firms' workers $\left(V_{t-1}^{L}\right)$, capital firms' workers $\left(V_{t-1}^{K}\right)$ and $\mathrm{R} \& \mathrm{D}$ employees $\left(V_{t-1}^{E}\right)$, computed respectively as follows:

$$
\begin{aligned}
& V_{t-1}^{L}=\sum_{l=1}^{\Lambda} V_{l, t-1}^{L} \\
& V_{1, t-1}^{L}=\left[\left(1+u^{l}\right) \frac{1}{A_{t-2}} \min \left\{Q_{t-1}^{d} ; D K_{t-2}\right\}\right]-L_{t-2}^{1} \\
& V_{l, t-1}^{L}=L_{t-1}^{l-1} \nu^{1-l}-L_{t-2}^{l} \quad \forall l \geq 2 \\
& V_{t-1}^{K}=\sum_{l=1}^{\Lambda} V_{l, t-1}^{K} \\
& V_{1, t-1}^{K}=\left[\left(1+u^{K}\right) \frac{K_{t-1}^{D}}{A^{K}}\right]-L_{t-2}^{k_{1}} \\
& V_{l, t-1}^{K}=L_{t-1}^{K_{l-1}} \nu^{1-l}-L_{t-2}^{K_{l}} \quad \forall l \geq 2 \\
& V_{t-1}^{E}=L_{t-1}^{E}-L_{t-2}^{E} .
\end{aligned}
$$

Therefore, the friction in the hiring process $\left(\epsilon_{L}\right.$ and $\epsilon_{M}$ in the labour demand (equations 6 and 24$)^{9}$ determines the difference between open vacancies and actual number of workers, as shown also in Fagiolo, Dosi, and Gabriele (2004).

\subsection{Demand}

The demand side of the model represents the mechanisms by which disposable income, generated at the micro-level as wages and distributed profits, is converted into monetary revenues and physical sales for the firm. Workers are grouped into income-consumption

\footnotetext{
${ }^{8}$ Börsch-Supan (1991) provides estimates on the German labour market using the hyperbolic form.

${ }^{9}$ This can also be interpreted as labour market friction, which, in matching models, determines the level of unemployment as a function of the number of matches and vacancies. In our model the number of matches corresponds to the workers actually hired (function of $\epsilon_{L}$ and $\epsilon_{K}$ ).
} 
classes, which constitute aggregate demand. Each class is assumed to contain consumers that are homogeneous with respect to income and preferences.

We assume therefore that social and income factors identify consumer classes, an assumption often made in households surveys for marketing studies (see e.g. CACI, 2005). We assume these factors to be linked to the hierarchical structure of the business organisation and to the income it generates: all workers in the same tier are members of the same class. The model allows for an exogenous division of expenses allocated to different needs for each class, for example, for food, housing, entertainment, and so forth. However, within the context of this paper, we analyse the model based on a single need ${ }^{10}$ and therefore we omit from the description the indication for different needs.

Each class $z \in\left\{0,1, \ldots, \Lambda_{t}\right\}^{11}$ can avail itself of a disposable income composed of current wages and share of profits. The level of consumption for each class is a convex combination of current and past disposable income. The consumption for each class is distributed across firms' revenues on the basis of consumers' preferences. Since consumer choice relies on a stochastic error, we perform a number of repetitions of the purchasing routine for each class. Finally, after each class has consumed, firms compute the quantity sold and their revenues.

In the following sections we describe the variables related to the demand routine: consumer classes disposable income, product definition and consumer choice.

\subsubsection{Total Income and classes' disposable income}

At each time step ${ }^{12}$ total income is the sum of the wages paid to workers and engineers, $\left(W^{w}\right)$ and the distributed profits, or premiums $\left(W^{\psi}\right)$.

$$
\begin{aligned}
W^{w} & =\sum_{l=1}^{\Lambda} \sum_{f=1}^{F} L_{f}^{l} w_{f}^{l}+\sum_{l=0}^{K_{\Lambda}} \sum_{g=1}^{G} L_{g}^{K_{l}} w_{g}^{K_{l}} \\
W^{\psi} & =\sum_{l=2}^{\Lambda} \sum_{f=1}^{F} L_{f}^{l} \psi_{f}^{l}+\sum_{l=2}^{K_{\Lambda}} \sum_{g=1}^{G} L_{g}^{K_{l}} \psi_{g}^{K_{l}}
\end{aligned}
$$

where $l=0$ in the capital sector firms indicates the engineers. The share of income for class $z$ is then a share of both wages and premiums:

$$
W_{z, t}=\chi_{z}^{w} W^{w}+\chi_{z}^{\psi} W^{\psi}
$$

where $\chi_{z \neq 0}^{w}=\frac{\sum_{f=1}^{F} L_{f}^{z} w_{f}^{z}+\sum_{g=1}^{G} L_{g}^{K z} w_{g}^{K z}}{W^{w}}$ is the share of total wages paid by firms to members of class $z$ and $\chi_{z}^{\psi}=\frac{\sum_{f=1}^{F} L_{f}^{z} \psi_{f}^{z}+\sum_{g=1}^{G} L_{g}^{K z} \psi_{g}^{K z}}{W^{\psi}}$, for higher classes, is the share of the premiums. The shares are computed considering firms from both the manufacturing and capital sectors; $\chi_{0}^{w}=\frac{\sum_{g=1}^{G} L_{g}^{E} w_{g}^{E}}{W^{w}}$ is the income share of the class of engineers.

\footnotetext{
${ }^{10} \mathrm{We}$ mention this feature of the model to highlight its flexibility and potential future uses. However, the nature, origin and evolution of needs are still controversial, and their relevance (as one anonymous referee correctly noted) is not generally accepted. Here, we ignore the role of needs because this study is not concerned with issues related to qualitative changes in demand.

${ }^{11}$ Where $\Lambda_{t}$ is the number of tiers of the larger firm in the market, and $z=0$ is the class of engineers in capital sector firms.

${ }^{12} \mathrm{We}$ omit the time index for clarity.
} 
Class consumption is a convex combination of current and past income. We implicitly assume that the consumption pattern is based on the convergence of the changes in disposable income over the medium term:

$$
C_{z, t}=\gamma C_{z, t-1}+(1-\gamma) W_{z, t}
$$

where $\gamma \in[0,1]$ is a parameter determining the 'speed' of adjustment of consumption to variations in income.

\subsubsection{Product definition}

Drawing on the work of Ciarli and Valente (2005), we consider that the micro-dynamics of production and consumption patterns rely on the product defined as a vector of characteristics, which satisfies user needs, in line with the Lancasterian (Gorman, 1959; Lancaster, 1966b; Lancaster, 1966a) and post-Lancasterian (Saviotti and Metcalfe, 1984; Gallouj and Weinstein, 1997) approach to consumer theory. As mentioned above, each manufacturing firm $f \in\{1,2, \ldots, F\}$ produces only one product. Each product satisfies one or more consumer needs $n \in\{1,2, \ldots, ; N\}$, defined over a vector of the characteristics $m_{n} \in\left\{1,2, \ldots, M_{n}\right\}$ which quantifies the quality level of the 'service(s) that each characteristic $i_{n, m}$ provides to the consumers:

$$
\left(\begin{array}{c}
i_{1,1} \\
\vdots \\
i_{n, 1} \\
\vdots \\
i_{n, m} \\
\vdots \\
i_{n, M} \\
\vdots \\
i_{N, M}
\end{array}\right)
$$

In the present paper we limit our analysis to changes in the productivity embedded in capital on the supply side, and in income on the demand side. Therefore, we are not concerned with the evolution of consumer tastes, and we fix the number of needs $n$ at 1 . Also, we assume that product characteristics are heterogeneous across firms, but constant through time. We consider only two characteristics $m$, one for the price $\left(i_{p}\right)$ of the product and one for its quality $\left(i_{q}\right)$. To simplify the notation we ignore the needs suffix $n$.

\subsubsection{Consumers behaviour and firms sales}

Having determined the composition of disposable income as a function of firm organisation and employment, production as a function of technology and demand, and the characteristics of the goods produced, we are left with a definition of consumer behaviour that decides firms' individual demands. 
We model bounded rational consumption behaviour inspired by the literature on experimental psychology, which has the properties of empirically observed behaviour (Gigerenzer, 1997; Gigerenzer and Selten, 2001) ${ }^{13}$. The original proposal, which resembles lexicographic preferences in the economic literature, has been elaborated to specifically accommodate consumers' purchasing decisions (Valente, 1999).

The model implements independently the purchasing decisions of consumers in each class $^{14}$. The consumers in a class are divided into $H \in N^{+}$groups with equal shares of class income $\frac{W_{z, t}}{H}$. First, a group of consumers in a class assigns to each firm $f$ a couple of perceived values for the price and quality of its good, $i_{f, m}^{*}=N\left(i_{f, m}, \sigma^{i} i_{f, m}\right)$, where $N(\ldots)$ indicates a draw from a normal random function with the specified parameters, and $\sigma^{i}$ determines the 'error' variance ${ }^{15}$. Repetition of the same choice $H$ times assures random evaluation of the firm's product.

Then, consumers select only the products that (appear to) score equivalent to the best product for each characteristic, i.e. lowest price, highest quality. The equivalence criterion is determined as a range $v_{z, m}=(0,1]$ : the perceived value of a product characteristic $i_{f, m}^{*}$ is considered equivalent to the best (perceived) product characteristic $i_{B, m}^{*}$ if the difference between the two values is smaller than a given percentage $v_{z, m}$. Formally ${ }^{16}$ :

$$
i_{f, m}^{*} \equiv i_{B, m}^{*} \Leftrightarrow\left|i_{f, m}^{*}-i_{B, m}^{*}\right|<\left(1-v_{z, m}\right) \cdot i_{B, m}^{*}
$$

The parameter $v$ can be interpreted as a tolerance level for products whose characteristics are of with less-than-optimal quality. For example, when $v=1.0$ the consumers group discards any product with a perceived value even slightly less than optimal. For $v=0.6$, on the other hand, the consumers group is indifferent over goods that are at least $60 \%$ as good as the optimal good.

The consumption routine always identifies one or more producers, and at least the best one.

Indicating with $F *_{\iota, z} \leq F$ the elements of a set of firms selected by the group $\iota$ $(\iota \in\{1, \ldots, H\})$ of a given class $z$, each firm is then assigned an equal share of the purchase $y_{t}^{\iota, z}$. We obtain the total units sold $\left(Y_{t}\right)$ for a firm by cumulating its sales over all groups and classes:

$$
Y_{t}=\frac{1}{p_{t}} \sum_{z=1}^{\Lambda_{t}} \sum_{\iota=1}^{H} y_{t}^{\iota, z} \frac{W_{t}^{z}}{H}
$$

\footnotetext{
${ }^{13}$ The algorithm implemented, devised to represent generalised decision making, respects the requirements of many findings in experimental psychology, such as generating a simple and explicit motivation for a decision (Shafir, Simonson, and Tversky, 1993).

${ }^{14}$ As noted, the routine is generally applied for each need defined in the configuration of demand. This is not necessary here because our model is configured with only one need for each class.

${ }^{15}$ The reader may object that price, unlike quality, is generally easy to assess. However, it is frequently the case that consumers fail to assess the true costs of a purchasing option (e.g. maintenance and usage costs). Moreover, this method allows us to represent the heterogeneity within a class.

${ }^{16}$ The expression needs to take into account that best price is a minimum value, while highest quality is a maximum value.
} 
with

$$
y_{t}^{\iota, z}=\left\{\begin{array}{l}
\frac{1}{F_{\iota, z}^{*}} ; \forall \text { firms } f \in\left\{F_{h, z}^{*}\right\} \\
0 \text { otherwise }
\end{array}\right.
$$

These sales $\left(Y_{t}\right)$ are used by the final goods firms to set their expectations for the next period's demand $\left(Y_{t+1}^{e}\right.$, see equation 1$)$.

\section{Results}

This section analyses the model properties in terms of growth and income distribution, and their relation, given the assumptions on initial conditions (Section 3.1). We focus first on the microeconomic dynamics (Section 3.2) and second on how these endogenously generate the aggregate growth and income distribution dynamics (Section 3.3).

We limit our discussion to the economically relevant results from the model, keeping the technical details of the analysis to a minimum. Further details on the results, including, for example, analysis of the sensitivity to randomness, and stability conditions with respect to a number of structural parameters, can be found in Ciarli, Lorentz, Savona, and Valente $(2008)^{17}$.

\subsection{Initialisation}

The main aim of the analysis is to check whether the interactions among the microbehaviours formalised above generate sensible results at aggregate level. In order to focus the discussion on the micro economic effects, we rely on an initialisation with minimal heterogeneity across firms.

The economy represented in the following exercise is composed of $f=\{1,2, \ldots, 50\}$ firms in the manufacturing sector. We assume that the number of firms does not change over time ${ }^{18}$.

Each firm produces a good that satisfies a single need $n=\{1\}$ evaluated along two characteristics, price $\left(i_{p}\right)$ and a catch-all index of quality $\left(i_{q}\right)$. Firms initially differ only with respect to the quality of the service provided, uniformally distributed across firms $i_{q} \sim U(98 ; 102)$, and are identical with respect to all other initial conditions: product inventories, expected sales, initial demand, mark-up, stock of capital, vintage productivity, wages, and so on. At this stage we do not take account of any relation between product price and quality: given the way that consumer preferences are set (see below), relative

\footnotetext{
${ }^{17}$ The simulated data and the files implementing the model are available on request from the authors. The simulation program was implemented using Lsd (Valente, 2008), which allows even non-expert programmers to easily investigate an existing model, replicate predefined results and generate new ones.

${ }^{18}$ This is a strong assumption, and ideally we need to analyse the model behaviour abstracting from possible spin-offs or entry of new firms. Both sources of market dynamics would require the addition of several ad hoc elements, either in the form of incentives to split production (which are not only cost based) or in the form of a full initialisation of the features of new firms. We believe that such an extension would require full analysis, in a self standing paper.
} 
differences in quality across firms are much smaller than the price differences generated by the model dynamics. However, in the conclusions we briefly report on the results that we obtained when the relative differences in quality across firms are much larger, and a positive relation between price and quality is introduced.

All firms employ a number of first tier workers necessary to cover the initial demand, which is identical for all the firms, and an executive (second tier worker) to manage the firm. The tier multiplier $(\nu)$ and the wage multiplier $(b)$ are set at values that lie within the observed boundaries (Simon, 1957; Lydall, 1959; Prescott, 2003), respectively 5 and 2. In referring to the tier multiplier Simon (1957, p.32) states that "this number varies within only moderate limits in a given company, and even among a number of companies. At executive levels it is seldom less than three, and seldom more than ten, and usually lies within narrower bounds". Similarly, he argues [p. 33] that "the value of $b$ can change from situation to situation, but one can find figures quoted in the range of 1.25 to 2 . While we would expect to encounter instances of larger or smaller ratios, averages can be expected to be relatively stable". We choose an intermediate value for $\nu$ and the maximum value for $b^{19}$

The capital sector is composed of $g=\{1,2, \ldots, 15\}$ firms, which are initialised as homogeneous competitors, with an initial first tier worker, a firm manager, and an engineer carrying out R\&D activity, paid from the firms' previous accrued profits. Capital producers initially produce the same vintage, with the same productivity, and have no stock of capital goods to sell.

On the demand side, the labour structure in the final and capital sectors defines three initial classes of consumers: engineers (employed by the capital sector), first tier workers, and a tier of managers. Starting from the first period, workers contribute to their class's total income from the pay received (wages, and profit shares/premiums). The three initial income/consumption classes are assumed to have different preferences with respect to the two product characteristics: first tier workers have a high tolerance towards quality $\left(v_{1, q}=0.1\right)$, but are highly sensitive to even small price differences $\left(v_{1, p}=0.9\right)$. For each following class of managers $(z+1)$ tolerance of shortfalls in quality reduces and tolerance towards price increases by a fixed multiplier $(\varsigma): v_{z+1, q}=(1-\varsigma) v_{z, q}+\varsigma \cdot v_{q}^{\max }$ and $v_{z+1, p}=(1-\varsigma) v_{z, p}-\varsigma \cdot v_{p}^{\min }$, where $v_{q}^{\max }$ and $v_{p}^{\min }$ are the boundaries of the possible tolerance levels with respect to product quality and price, respectively. Finally, all worker/consumer classes perform $H=50$ samples of the purchasing routine.

Unless stated otherwise, the results discussed in the rest of the section are averages obtained over 10 simulation runs with different random properties. In Ciarli, Lorentz, Savona, and Valente (2008) we show that this is a sufficient number of runs to control for variability due to random events.

\footnotetext{
${ }^{19}$ This is because, as frequently pointed out after presentations of this paper, and as indicated by a large amount of evidence, wage gaps have increased substantially in the last 50 years.
} 


\subsection{Micro and meso-dynamics}

After a few time steps from the start of the simulation, the economic system settles to a stable growth path. We observe that firms' market shares are distributed proportionally to the characteristics of their products, generating an increasing income for consumers via wages and distribution of profits, which spurs further employment and, consequently, sustains moderate growth. However, the simulations reveal many 'slow' micro-dynamics, whose effects are generated after periods of building-up, and which eventually lead to changes (more or less dramatic) in the initially stable growth patterns. We can identify three different points in time when the economy undergoes substantial change, as shown in figure 1.

[Figure 1 about here.]

At around time step 400, we observe an increase in the minimum wage, which rapidly translates into higher average income and prices. This increase in the minimum wage is due to the slow reaction of labour supply to increasing demand for labour (high number of non-matched vacancies). This translates into an increasing wage, which, in the absence of productivity improvements (if we exclude the initial investment in capital), directly increases consumers prices. When these reach the negotiation level, a series of discrete changes in the minimum wage occurs. However, this does not change the slow pattern of growth, as it is a monetary adjustment with no real and lasting effects.

Though different in nature (the minimum wage is not affected), the events that occur at around time 900 do not induce any relevant (immediate) change in the growth pattern. The continuous growth of some of the firms requires that they employ a further tier of managers (i.e., the number of first tier managers reaches the threshold $\nu$ ). This leads to a rapid increase in the level of the wages paid by firms, which starts to erode their previous competitive advantage (and which allowed these firms to grow faster). Extra costs force these firms to raise their prices. Since a comparatively larger share of consumption comes from the first tier workers (highly sensitive to prices), market shares quickly shift to favour smaller firms. These latter in turn begin to approach the dimensional threshold above, for which they also need an additional manager tier, so that the process of erosion of competitive advantage affects them as well. Soon after this period of imbalance, the system returns to its previous configuration, with the only lasting effect being lower aggregate labour productivity, caused by the higher cost weighting on the same unit productivity (firm level productivity is obviously unvaried).

Productivity remains stagnant due to the fact that, up to period 1200, no technological change occurs. The level and growth of consumption are not sufficient to require final firms to invest in new capital. This lack of demand in turn affects capital firms, which do not have the resources to invest in $R \& D$ and produce new capital goods with higher embedded productivity.

However, shortly before time 1200, further increases in firm size and changes in the organisation of production occur, following the formation of a critical mass of consumption. 
The differences that firms have established over time are reflected in the larger gaps in their growth rates. Therefore, when just before period 1200 some firms have grown to include a fourth tier of workers, they will be at a price disadvantage against competitors for a few time periods. The critical mass of consumption that has cumulated over time thus generates an unexpectedly high demand for those firms that still enjoy a price advantage (due to lower labour costs), and which are addressed by most consumers. Such an increase in demand requires an increase in capital stock. In turn, the need for investment generates an intermediate demand that allows capital firms to start investing in R\&D and deliver capital goods with higher embedded productivity.

The manufacturing firms that had lower prices thus also cumulate the advantage of producing with newer capital vintages. When growing larger, they expand their organizational structure (increasing average wages) and enjoy productivity growth. The overall impact for those firms is a reduction in labour costs and prices. The resulting pattern of growth shows a marked increment of average productivity, reflected also in falling prices. Also, the overall market structure is completely altered (Figure 2).

[Figure 2 about here.]

Figure 2 shows in fact a marked increase in concentration, prompted by a symmetric large increase in price volatility, indicated by the standard deviation of prices. The reason for this is that the stochasticity of innovation has an initially reinforcing effect: more productive firms reduce their prices even more, and are targeted by the consumption class of first tier workers. These firms are then more likely to invest in new capital, and tend, therefore, ceteris paribus, to grow even larger. This latter dynamic allows a cyclical turnover of firms' market shares, when growing firms pair productivity gains with overgenerous wages for managers. The market remains concentrated. It should be noted also that the queueing system for capital purchases shuffles the situation, so that when the best performing capital producers have a very full order book, then firms will prefer to buy capital with lower embedded productivity, but which could be brought into operation more quickly, in order to satisfy customer demand.

\subsection{Patterns of growth and income inequality}

The previous section provided a summary of the main dynamics of the 'micro' level of the model. We now present the simulation results from a macro-economic perspective, looking at the type of growth and income distribution generated by the model.

The results of the numerical simulations of the model, based on the micro dynamics described above, endogenously reproduce a typical long run growth pattern, à la Maddison, which shows a steep take-off after a large number of time steps. Figure 3 shows the GDP series for 100 simulation runs - in logarithmic scale - and their average value. In our simplified model of a closed economy, GDP is the sum of final firms' production and investment. 
[Figure 3 about here.]

The simulation results show two clear and distinctive growth patterns, in which the turning point is around step 1250. During the first stage, GDP is characterised by a stable pattern of growth. This occurs after initial capital investment by the manufacturing firms, which generates the initial demand. In this first stage the increase in GDP is driven by what we can term purely demand-led growth: growth in income, through wages and population increases, which induces increased spending for final consumption, and firm expansions which push up wages and employment, inducing a cumulative pattern. In this state of equilibrium growth, investment grows at the rate of capital depreciation and population increase. However, population growth is endogenous in our model. Firms use their profits first to invest, and then redistribute any excess to consumers which contributes to increased demand. Notice that, unlike standard growth models, the implicitly assumed free access to the credit market allows growth in consumption and investments to coexist, and explains the sustainability of the stable growth pattern. Yet, in this stage, the final demand is not sufficiently large to generate enough profits in the capital sector — via demand in the machinery sector - to be spent on hiring R\&D workers, thus failing to generate productivity-enhancing innovations.

In the second stage of growth, productivity starts to increase (see Figure 1), though with high differentiation across firms. This phase shows an increase in variety, with growth rates differing both within and among simulation runs. The results from $R \& D$, in fact, are stochastic, and therefore different simulation runs produce relatively different patterns. The mechanism behind this phase of growth rate that generates a take-off is typically Kaldorian. We refer to this second stage as the cumulative causation growth: the selection of a few firms, together with a critical level of demand, translates into large capital investment for the selected firms, which generates profits and investment in new technology with increased productivity. The growth in productivity then implies a reduction in production costs and prices, an increase in profitability and thus of the income redistributed to households. Both, in turn, sustain the expansion of effective demand via a reduction in prices and an expansion in available income (Kaldor, 1966).

The two stylised growth patterns are accompanied by a two-stage evolution of inequality. Figure 4 shows the Atkinson index series from 100 independent runs with different random behaviour, and their averages. The Atkinson index of inequality $\left(\mathcal{A}_{t}\right)$ is computed as follows:

$$
\mathcal{A}_{t}=1-\frac{1}{\sum_{z=1}^{Z} \frac{W_{z, t}}{L_{z, t}}}\left[\frac{1}{\sum_{z=1}^{Z} L_{z, t}} \sum_{z=1}^{Z}\left(\frac{W_{z, t}}{L_{z, t}}\right)^{1-\varrho}\right]^{\frac{1}{1-\varrho}}
$$

where $W_{z, t}$ is the total income for consumer class $z, L_{z, t}$ is the total number of workers in class $z$, and $\varrho$ is the measure of inequality aversion. Provided that we are not measuring an empirical level of inequality, we use an intermediate value of $\varrho=0.5$.

[Figure 4 about here.] 
To the extent that growth depends only on the 'short' loop of workers' spending (demand-led growth phase), the only source of inequality is a new class of consumers (a new tier of managers) enjoying higher salaries and bonus shares. The distribution of income is then highly stable for a given organisation of production, and discrete changes in observed inequality depend on the introduction of new manager tiers.

However, when manufacturing firms begin to differ in terms of size and profits (cumulative casuation growth phase), the skewness of the wage distribution increases and, together with the increasing distribution of profits, generates the higher average inequality observed. The volatility characterising this stage of growth at micro level in terms of productivity and market dynamics also affects income distribution, which follows a cyclical pattern $^{20}$.

At the end of the simulated periods, we found that the model generates the typical Paretian distribution of top incomes ${ }^{21}$. In Figure 5 we plot the Lorenz curve for an illustrative simulation run. Most of the economic wealth is concentrated in a small number of workers in the executive tiers.

[Figure 5 about here.]

Moreover, as reported, for example, by Gottschalk and Smeeding (1997) and Cornia (2003), most of the inequality in distribution observed in our simulated data is explained by earnings inequalities ${ }^{22}$. Our results are also in line with the finding that "Earnings inequality has risen also because of the fall of minimum wages relative to the average" (p.6 Cornia, 2003). An indication of this effect can be seen in the average income and minimum wage series in Figure 1.

Finally, we are left with the relation between GDP and inequality. In Figure 6 we plot the values of the Atkinson index, for given levels of GDP (at constant prices, in log scale).

[Figure 6 about here.]

The figure shows that our model, notwithstanding its limitations, is able to generate a sort of Kuznets curve, albeit the negatively sloped portion is shorter than that predicted in the theory. This result shows that, while higher levels of production are matched by higher levels of inequality, after the income level reaches a threshold the inequality stops growing, and rather begins to fall. The increasing part is clearly due to the increasing wage differential, while at very high levels of income and demand, firms sacrifice profit shares to capital investment.

\footnotetext{
${ }^{20} \mathrm{An}$ increasing and oscillating pattern of inequality is reported, for example, by Fiaschi and Marsili (2006) for the Gini coefficient computed on Italian labour income. See, also, the evidence on earnings dispersion over the last 40 years, in different OECD countries, in Atkinson (2007).

${ }^{21}$ See for instance Fiaschi and Marsili (2006), Clementi and Gallegati (2005) and Klass, Biham, Levy, Malcai, and Solomon (2006).

${ }^{22}$ Both Gottschalk and Smeeding (1997) and Cornia (2003), refer to high income countries, which is the reference for the last step of our simulations.
} 
It is interesting to look at the relation between inequality and GDP growth, which is still highly controversial on both empirical and theoretical grounds (among many others, Eicher and Turnovsky, 2007; Aghion, Caroli, and García-Peñalosa, 1999). We plot this relation in Figure 7.

[Figure 7 about here.]

The figure shows that higher levels of inequality increase GDP growth in the following period. This is easily explained in our model at the micro level: first, recall that demand plays a crucial role in our model, determining the critical level above which selection of firms prompt take-off and sustained growth. We also know that when demand increases, there is an increase in both average wages (through the new tier of executives) and employment (though at a slower pace once technological progress is possible due to investment). We do not make any assumptions about the elasticity of consumption across wage classes. We only assume a difference in preferences which, on average, would push first tier workers to be more selective about prices than managers. Therefore, if there were distributional mechanisms at work, and the increase in average wages was equally distributed across the new class of executives and the other working tiers, the level of the demand would remain the same. The same would apply to the rate of growth.

There is one caveat here, which is that if it is verified that different classes of income have difference preferences in terms of prices and qualities from the beginning, then the initial difference in income, and thus in preferences, is what triggers the take-off, via the selection of firms on the basis of their costs. But, in our model, further maintenance of inequality cannot be justified by a higher growth rate.

\section{Concluding remarks and a research agenda}

\subsection{The scope of the analysis: a summary}

In this paper we investigated the relation between technological and organisational change, income distribution and the dynamics of consumption affecting macro-economic growth. We developed an agent-based micro-founded model with the aim of integrating these phenomena within a coherent theoretical framework. Micro-economic behaviours are modelled in line with the large and consolidated evolutionary theory of technical change and economic growth, while the macro-framework borrows from the structuralist literature including the presence of a capital sector and endogenous consumption classes. In terms of these two streams of literature, the main original feature of the model is the explicit introduction of micro-mechanisms representing income distribution, one of the main channels between changes in the organisation of firms and changes in consumption patterns.

The results of the simulations - reported in detail above - are driven by the structural conditions and interaction mechanisms formally represented. We summarise these as follows: 
First, the organisation of production - given by the required number of workers that a manager can supervise and the number of tiers characterising the firm - generates price dispersion, defines different wage classes, and directly affects income distribution.

Second, the formation of wage classes and the related income structure, determine differences in consumption preferences.

Third, the differences in consumption preferences play a crucial role as soon as firm dynamics generate a sufficient heterogeneity. Heterogeneity of firms and consumption patterns generates changes in the market structure (i.e. oligopolistic competition), and the income structure (i.e. higher profits).

Fourth, the composition of production in terms of product characteristics determines the heterogeneity required for consumer choice. In this paper we observed only the emergence of price differences (through process innovation); differentiation in terms of quality (product innovation) or structural differences in terms of different sectors that satisfy different needs, would stimulate similar selection mechanisms.

As already mentioned, these results relate to analysis of the main aggregate properties of the model. As a preliminary counter-factual, we analysed the effects of different initial structural conditions, to check for sensitivity of the model to the crucial parameters. These are not reported in full due to space constraints. We provide only a brief summary and direct the interested reader to Ciarli, Lorentz, Savona, and Valente (2008). We analysed how the results obtained in this paper change with respect to a number of parameters that determine structural properties: (i) product characteristics and mark-up values (composition of production); (ii) consumer preferences and their differences across classes (consumption patterns); (iii) the multiplier defining the number of workers per executive and the rate of process innovation (organisation and production structure); and (iv) the multiplier determining earnings distribution (income structure). The results confirm the relevance of the initial structural conditions on both economic growth and distribution. While the model always shows endogenous growth under any combination of the structural conditions, the relation is highly non-linear. It ranges from exponential growth, similar to what we found in this paper, to an almost stagnant economy. Also, the effect on inequality is mostly non-linear, as is the relation between growth and inequality (we obtain high growth with a rather equal economy, as well as highly uneven economic stagnation).

\subsection{Research agenda}

The results obtained and discussed above - both those from our study and those related to the effects of structural parameters (Ciarli, Lorentz, Savona, and Valente, 2008) are encouraging and worthy of further investigation. We plan to extend the model by endogenising some of the presently parameterised structural conditions, in order to analyse the states under which structural changes emerge, and their dynamic effects which mainly relate to:

- Final demand: the (radical) change in the product characteristics (i.e. product innovation), the conditions for their emergence and the effects on consumption (i.e. 
consumer perception, quality and time of reaction to novelty, etc.). The model would provide micro-foundation for the relation between variety and economic growth, in line with some of the findings in the literature (Saviotti and Pyka, 2004; Saviotti and Pyka, 2008) for the macro-level;

- Linked to this, the relationship between product innovation and the creation and/or substitution of needs (i.e. evolution of consumer preferences). A recent and flourishing literature explores this domain (Witt, 2006; Witt, 2001), to which this model could originally contribute:

- Intermediate demand: changes in the organisation of firms and sectors (i.e. outsourcing, emergence of new inputs sectors, and changes in the inter-sectoral linkages).

All these issues are on our future research agenda, which will based on the fundamentals proposed in the present work. 


\section{References}

Abowd, J. M., F. Kramarz, and D. N. Margolis (1999): "High Wage Workers and High Wage Firms," Econometrica, 67(2), 251-333.

Aghion, P. (2002): "Schumpeterian Growth Theory and the Dynamics of Income Inequality," Econometrica, 70(3), 855-882.

Aghion, P., E. Caroli, and C. García-Peñalosa (1999): "Inequality and Economic Growth: The Perspective of the New Growth Theories," Journal of Economic Literature, $37(4), 1615-1660$.

Amendola, M., And J. L. Gaffard (1998): Out of Equilibrium. Oxford Clarendon Press.

Atkinson, A. B. (1997): "Bringing Income Distribution in From the Cold," The Economic Journal, 107(441), 297-321.

(2007): "The distribution of earnings in OECD countries," International Labour Review, 146(1-2), 41-60.

Aversi, R., G. Dosi, G. Fagiolo, M. Meacci, and C. Olivetti (1999): "Demand Dynamics with Socially Evolving Preferences," Industrial and Corporate Change, 8(2), 353-408.

Babutsidze, Z. (2007): "How Do Consumers Make Choices? A Summary of Evidence from Marketing and Psychology," Discussion paper, United Nations University.

BARro, R. (1991): "Economic Growth in a Cross Section of Countries," Quarterly Journal of Economics, 106(2), 407-443.

Blanchflower, D. G., And A. J. Oswald (2006): "The Wage Curve: An Entry Written for the New Palgrave, 2nd Edition," Discussion Paper 2138, IZA.

Blinder, A. (1991): "Why are prices sticky? Preliminary results from an interview study," American Economic Review, 81(2), 89-96.

Börsch-Supan, A. H. (1991): "Panel Data Analysis of the Beveridge Curve: Is There a Macroeconomic Relation between the Rate of Unemployment and the Vacancy Rate?," Economica, 58(231), 279-297.

Bottazzi, G., and M. Grazzi (2007): "Wage structure in Italian Manufacturing firms," LEM Working Paper Series 2007/05, Laboratory of Economics and Management, Sant'Anna School of Advanced Studies, Pisa.

Brown, C., And J. Medoff (1989): "The Employer Size-Wage Effect," Journal of Political Economy, 97(5), 1027ñ59. 
CACI (2005): ACORN User Guide.

Caroli, E., and J. Van Reenen (2001): "Skill-Biased Organizational Change? Evidence from a Panel of British and French Establishments," Quarterly Journal of Economics, 116(4), 1449-1492.

Cesaratto, S., F. Serrano, and A. Stirati (2003): "Technical Change, Effective Demand and Employment," Review of Political Economy, 5(1), 33-52.

Chiaromonte, F., and G. Dosi (1993): "Heterogeneity, Competition, and Macroeconomics Dynamics," Structural Change and Economic Dynamics, 4(1), 39-63.

Ciarli, T. (2005): "Patterns of Industrial Development in Costa Rica: Empirical 'Validation' of a Firm-Based Growth Model," Quaderni Deit 14/2005, Dipartimento di Economia Istitutzioni Territorio, Università di Ferrara, http://deit.economia.unife.it/quaderni/2005/14/14.pdf.

Ciarli, T., A. Lorentz, M. Savona, and M. Valente (2008): "Structural Change of Production and Consumption: A Micro to Macro Approach to Growth and Income Distribution," Working Paper LEM 2008/06, Laboratorio di Economia e Management.

Ciarli, T., And M. Valente (2005): "Firms Interaction and Industrial Development: A Simulation Model," in Clusters Facing Competition: The Importance of External Linkages, ed. by E. Giuliani, R. Rabellotti, and M. P. Van Dijk. Ashgate, Aldershot.

Clementi, F., and M. Gallegati (2005): "Power law tails in the Italian personal income distribution," Physica A, 350, 427-438.

Cooper, R., and J. Haltiwanger (2006): "On the Nature of Capital Adjustment Costs," Review of Economic Studies, 73(3), 611-633.

Cornia, G. (2003): "Changes in the Distribution of Income over the last Two Decades. Extent, Sources and Possible Causes," Discussion paper, Paper presented at the 2003 Annual Meeting of the Societ $\ddagger$ Italiana degli Economisti.

Cowan, R., W. Cowan, and P. Swann (1997): "A Model of Demand with Interactions among Consumers," International Journal of Industrial Organization, 15, 711-32.

Criscuolo, C. (2000): "Employer Size - Wage Effect: A Critical Review and an Econometric Analysis," SSRN eLibrary.

Deaton, A., And J. Muellbauer (1980a): "An Almost Ideal Demand System," The American Economic Review, 70(3), 312-326.

(1980b): Economics and Consumer Behavior. Cambridge University Press.

Denison, E. F. (1967): "Why growth rates differ," Brooking Inst. Washington D.C. 
- (1979): "Accounting for slower economic growth," Discussion paper, Brooking Inst. Washington D.C.

Doms, M., And T. Dunne (1998): "Capital Adjustment Patterns in Manufacturing Plants," Review of Economic Dynamics, 1, 409-429.

Dosi, G. (1982): "Technological paradigms and technological trajectories : A suggested interpretation of the determinants and directions of technical change," Research Policy, 11(3), 147-162.

Dosi, G., C. Freeman, R. Nelson, G. Silverberg, and L. Soete (1988): Technical Change and Economic Theory. Pinter, London.

Durlauf, S. N., And D. T. Quah (1998): "The New Empirics of Economic Growth," Discussion paper 384, Centre For Economic Performance, Prepared for the 'Handbook of Macroeconomics', Taylor J. and Woodford M. (eds.).

Eicher, T. S., And S. J. TuRnovsky (eds.) (2007): Inequality and Growth. Theory and Policy Implications, CESifo Seminar Series. MIT Press.

Fagiolo, G., G. Dosi, and R. Gabriele (2004): "Matching, Bargaining, and Wage Setting in an Evolutionary Model of Labor Market and Output Dynamics," Advances in Complex Systems, 14, 237-273.

Fazzari, S., R. Hubbard, and B. Petersen (1988): "Financing constraints and corporate investment," Brookings Papers on Economic Activity, 1, 141-195.

Fiaschi, D., And M. MARsili (2006): "The distribution of wealth: theoretical microfoundations and empirical evidence," Working Paper 2006-49, ECINEQ.

Galbraith, J. K. (1999): "Globalization and Pay," Proceedings of the American Philosophical Society, 143(2), 178-186.

Galbraith, J. K., J. Lu, and W. A. Darity (1999): "Measuring the Evolution of Inequality in the Global Economy," UTIP Working Paper 7, University of Texas at Austin - Lyndon B. Johnson School of Public Affairs.

Gallouj, F., and O. Weinstein (1997): "Innovation in Services," Research Policy, 26, $537-556$.

Gigerenzer, G. (1997): "Bounded Rationality: Models of Fast and Frugal Inference," ", Swiss Journal of Economics and Statistics, 133(2).

Gigerenzer, G., and R. Selten (2001): Bounded rationality: The adaptive toolbox. Mit Press.

Gorman, W. M. (1959): "Separable Utility and Aggregation," Econometrica, 27. 
Gottschalk, P., and T. M. Smeeding (1997): "Cross-National Comparisons of Earnings and Income Inequality," Journal of Economic Literature, 35(2), 633-687.

Hall, R., and C. Hitch (1939): "Price theory and business behaviour," Oxford Economic Papers, 2, 12-45, Reprinted in Wilson T and Andrews PWS (ed.), Oxford Studies in the Price Mechanism. Clarendon, Oxford. 1951.

Hall, S., M. Walsh, AND A. Yates (1997): "How do UK companies set prices?," Working Paper 67, Bank of England, http://papers.ssrn.com/sol3/papers.cfm?abstract_id=114948.

Idson, T. L., And W. Y. Oi (1999): "Workers Are More Productive in Large Firms," American Economic Review, 89(2, Papers and Proceedings), 104-108.

KAldor, N. (1957): "A Model of Economic Growth," Economic Journal, December, $65-94$.

(1966): Causes of the Slow Rate of Growth in the United Kingdom. Cambridge University Press, Cambridge.

Klass, O. S., O. Biham, M. Levy, O. Malcai, and S. Solomon (2006): "The Forbes 400 and the Pareto wealth distribution," Economics Letters, 90, 290-295.

Kurz, H. D., And N. Salvadori (1998): The Elgar Companion to Classical Economics. Aldershot, Edward Elgar.

LAnCASter, K. J. (1966a): "Change and Innovation in the Technology of Consumption," The American Economic Review, 56(1/2), 14-23.

(1966b): “A New Approach to Consumer Theory," Journal of Political Economy, $14,133-156$.

Llerena, P., And A. Lorentz (2004): "Cumulative Causation and Evolutionary Microfounded Technical Change: On the Determinants of Growth Rates Differences," Revue Economique, 55(6), 1191-1214.

Lorentz, A. (2008): "Sectoral Specialisation and Growth Rates Differences Among Integrated Economies," The Electronic Journal of Evolutionary Modeling and Economic Dynamics, Forthcoming.

Lorentz, A., And M. Savona (2008): "Evolutionary Micro-dynamics and Changes in the Economic Structure," Journal of Evolutionary Economics, 18(3-4), 389-412.

Lydall, H. F. (1959): "The Distribution of Employment Incomes," Econometrica, 27(1), $110-115$.

Maddison, A. (1987): "Growth and Slowdown in Advanced Capitalist Economies: Techniques of Quantitative Assessment," Journal of Economic Literature, XXV, 649-698. 
McCarthy, J., And E. ZakrajŠEk (2000): "Microeconomic Inventory Adjustment: Evidence From U.S. Firm-Level Data," FRB of New York Staff Report 101, Federal Reserve Bank of New York, https://federalreserve.gov/pubs/feds/2000/200024/200024pap.pdf.

Meade, J. E. (1963): "The Rate of Profit in a Growing Economy," Economic Journal, 73(292), 292.

Modigliani, F., and M. Miller (1958): "The cost of capital, corporation finance and the theory of investment," American Economic Review, 48, 261-297.

MontobBio, F. (2002): "An Evolutionary Model of Industrial Growth and Structural Change," Structual Change and Economic Dynamics, 13, 387-414.

Nelson, R., And S. Winter (1982): An Evolutionary Theory of Economic Change. Harvard University Press.

Nickell, S., L. Nunziata, W. Ochel, And G. Quintini (2002): "The Beveridge Curve, Unemployment and Wages in the OECD from the 1960s to the 1990s," Working paper, CEPR, LSE, London.

Nijkamp, P., And J. Poot (2005): "The Last Word on the Wage Curve?, Journal of Economic Surveys, 19(3), 421-450.

Oi, W. Y., And T. L. Idson (1999): "Firm Size and Wages," in Handbook of Labor Economics, ed. by O. Ashenfelter, and D. Card, p. 2165ñ2214. Elsevier Science, Amsterdam.

Pasinetti, L. L. (1962): "Rate of Profit and Income Distribution in Relation to the Rate of Economic Growth," Review of Economic Studies, 29(4), 4.

Pasinetti, L. L. (1981): Structural Change and Economic Growth: A Theoretical Essay on the Dynamics of the Wealth of the Nations. Cambridge University Press, Cambridge.

Petrongolo, B., And C. A. Pissarides (2001): "Looking into the Black Box: A Survey of the Matching Function," Journal of Economic Literature, 39(2), 390-431.

Prescott, E. S. (2003): "Firms, Assignments, and Earnings," Federal Reserve Bank of Richmond Economic Quarterly, 89(4), 69-81.

Rosen, S. (1981): "The Economics of Superstars," American Economic Review, 71(5), 845-858.

(1982): "Authority, Control, and the Distribution of Earnings," Bell Journal of Economics, 13(2), 311-323.

Saviotti, P., and J. S. Metcalfe (1984): "A Theoretical Approach to the Construction of Technological Output Indicators," Research Policy, 13, 141-15. 
Saviotti, P. P., and J. L. Gaffard (2008): "Preface for the special issue of JEE on 'Innovation, structural change and economic development'," Journal of Evolutionary Economics, 18(2), 115-117.

Saviotti, P. P., And A. Pyka (2004): "Economic Development by the Creation of New Sectors," Journal of Evolutionary Economics, 14(1), 1-35.

(2008): "Technological Change, Product Variety and Economic Growth," Journal of Evolutionary Economics, 18(3-4), 323-347.

Schumpeter, J. (1934): The Theory of Economic Development. An Inquiry into Profits, Capital, Credit, Interest and the Business Cycle. Harvard University Press., Cambridge, MA.

Shafir, E., I. Simonson, and A. Tversky (1993): "Reason-based Choice," Cognition, $49,11-36$.

SilverberG, G., and B. Verspagen (2005): "Evolutionary Theorizing on Economic Growth," in The Evolutionary Foundations of Economics, ed. by K. Dopfer, pp. 506539. Cambridge University Press.

Simon, H. A. (1957): "The Compensation of Executives," Sociometry, 20(1), 32-35.

Stiglitz, J. E. (1969): "Distribution of Income and Wealth Among Individuals," Econometrica, 37(3), 382-397.

Swann, G. (1999): "An Economic Analysis of Taste-A Review of Gary S. Becker: Accounting for Tastes," International Journal of the Economics of Business, 6(2), 281-296.

Teo, E., S. M. Thangavelu, and E. Quah (2004): "Singapore's Beveridge Curve: A Comparative Study of the Unemployment and Vacancy Relationshio for Selected East Asian Countries," Economic Survey of Singapore Second Quarter, Ministry of Manpower.

Tinbergen, J. (1975): Income Distribution: Analysis and Policies. North-Holland Pub. Co.

U.S. Census Bureau, . (2008): "Manufacturing and Trade Inventories and Sales," http://www.census.gov/mtis/www/mtis.html.

Valente, M. (1999): "Evolutionary Economics and Computer Simulation. A Model for the Evolution of Markets (Vol. 1: Consumer Behaviour and Technological Complexity in the Evolution of Markets," DPhil Dissertation, University of Aalborg, 1999.

(2008): "Laboratory For Simulation Development - LSD," Working Paper LEM 2008/12, Laboratorio di Economia e Management. 
Verdoorn, P. (1949): "Fattori che Regolano lo Svilluppo della Produttivitá del Lavoro," L' Industria, 1, 45-53.

Verspagen, B. (1993): Uneven Growth Between Interdependent Economies: Evolutionary Views on Technology Gaps, Trade and Growth. Avenbury.

(2004): "Structural Change and Technology. A Long View," Revue Economique, 55(6), 1099-1126.

Waldman, M. (1984): "Workers Allocation, Hierarchies and the Wage DIstribution," The Review of Economic Studies, 51, 95-109.

Wall, H. J., And G. Zoega (2002): "The British Beveridge curve: A tale of ten regions," Oxford Bulletin of Economics and Statistics, 64(3), 257-276.

WitT, U. (2001): "Learning to Consume - A Theory of Wants and the Growth of Demand," Journal of Evolutionary Economics, 11, 23-36.

(2006): "Evolutionary Economics and Psychology," Discussion paper, Max Planck Institute of Economics.

Yashiv, E. (2007): "Labor Search and Matching in Macroeconomics," Discussion Paper 2743, IZA. 


\section{A Tables}

[Table 1 about here.]

[Table 2 about here.] 


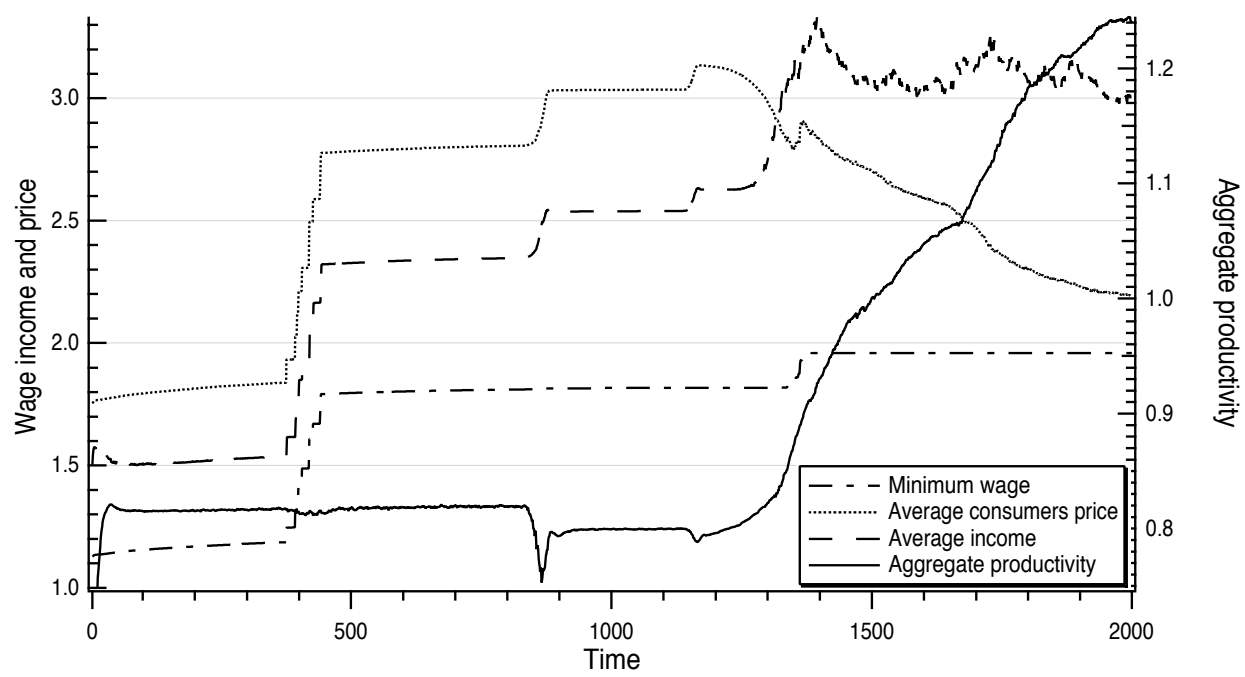

Figure 1: Aggregate productivity, minimum wage, average income and price. The average price (left axis) results from the minimum wage (left axis), the aggregate productivity (right axis), and the increase in organisational tiers. Average income is also plotted against the left axis.

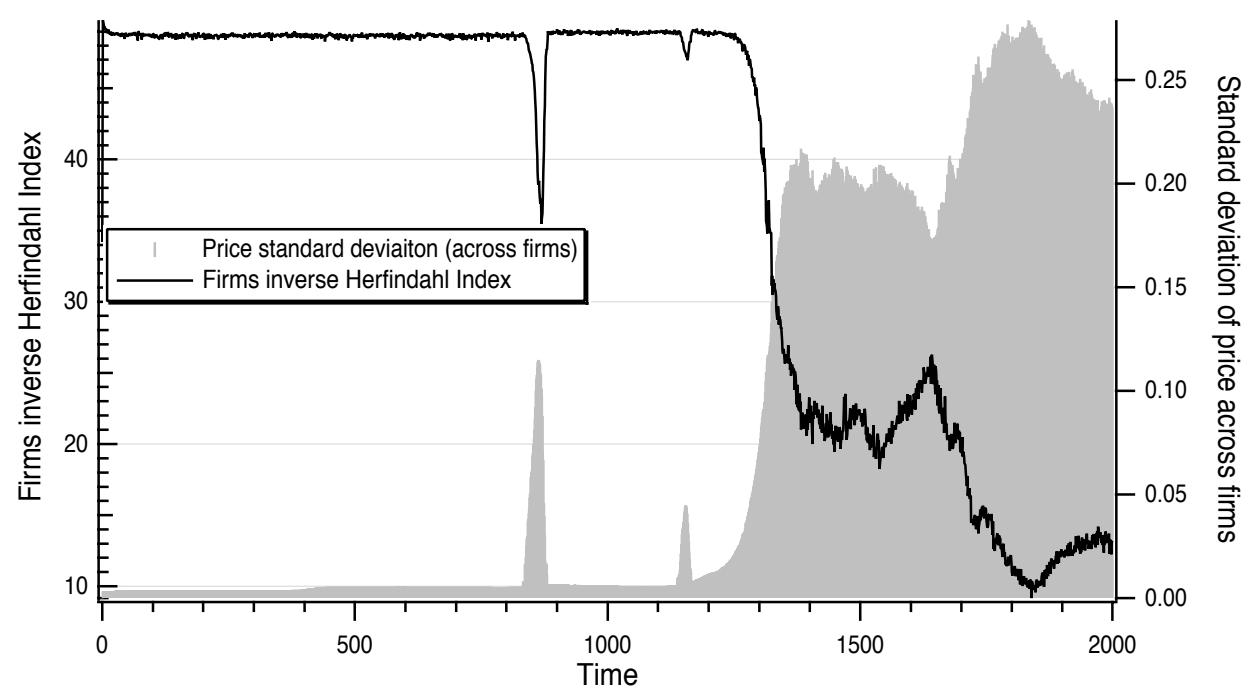

Figure 2: Firms dispersion and price dispersion. 


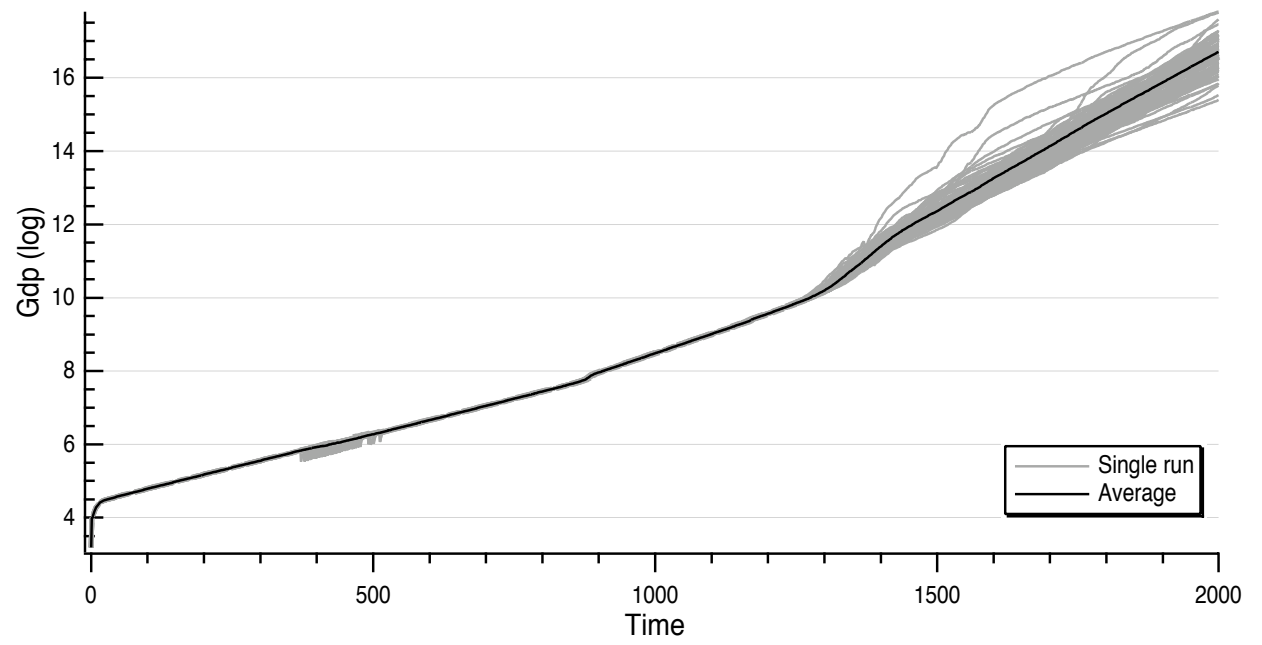

Figure 3: GDP (log) series: 100 runs and average. Series for 100 runs and average, in logarithmic scale, for 2000 time steps.

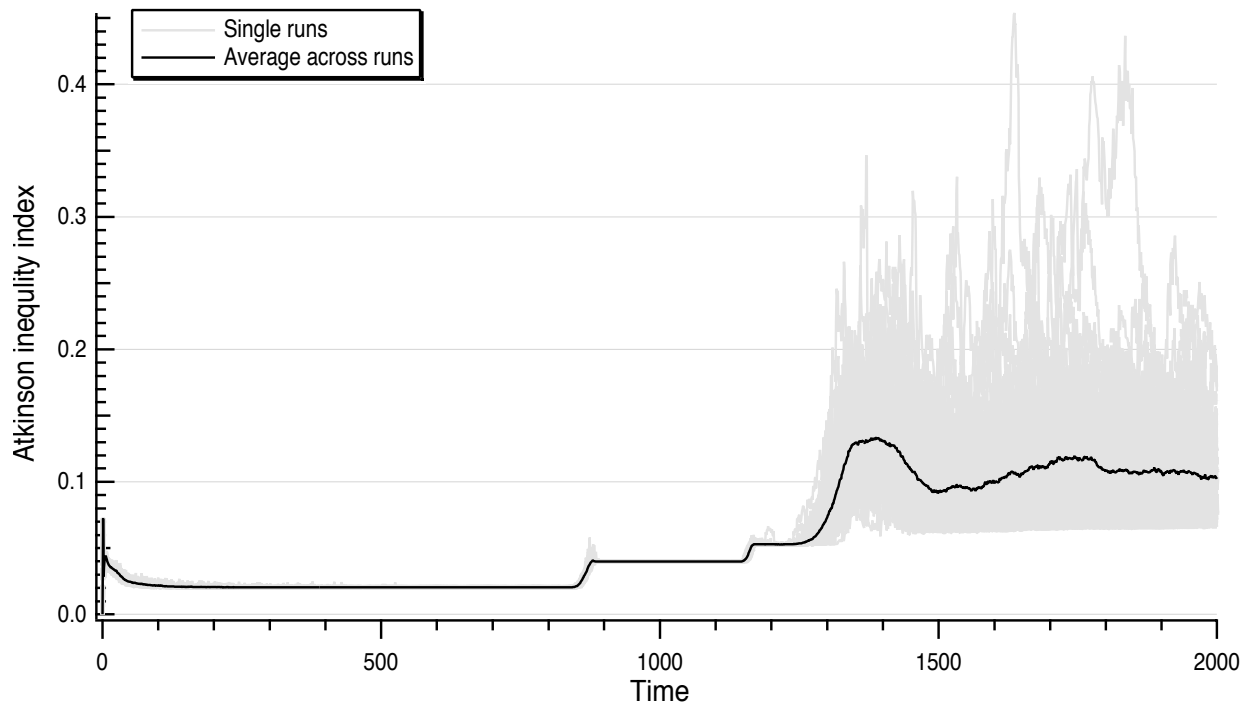

Figure 4: Atkinson inequality index. Series for the first 2000 simulation steps for 100 independent runs, and their average. 


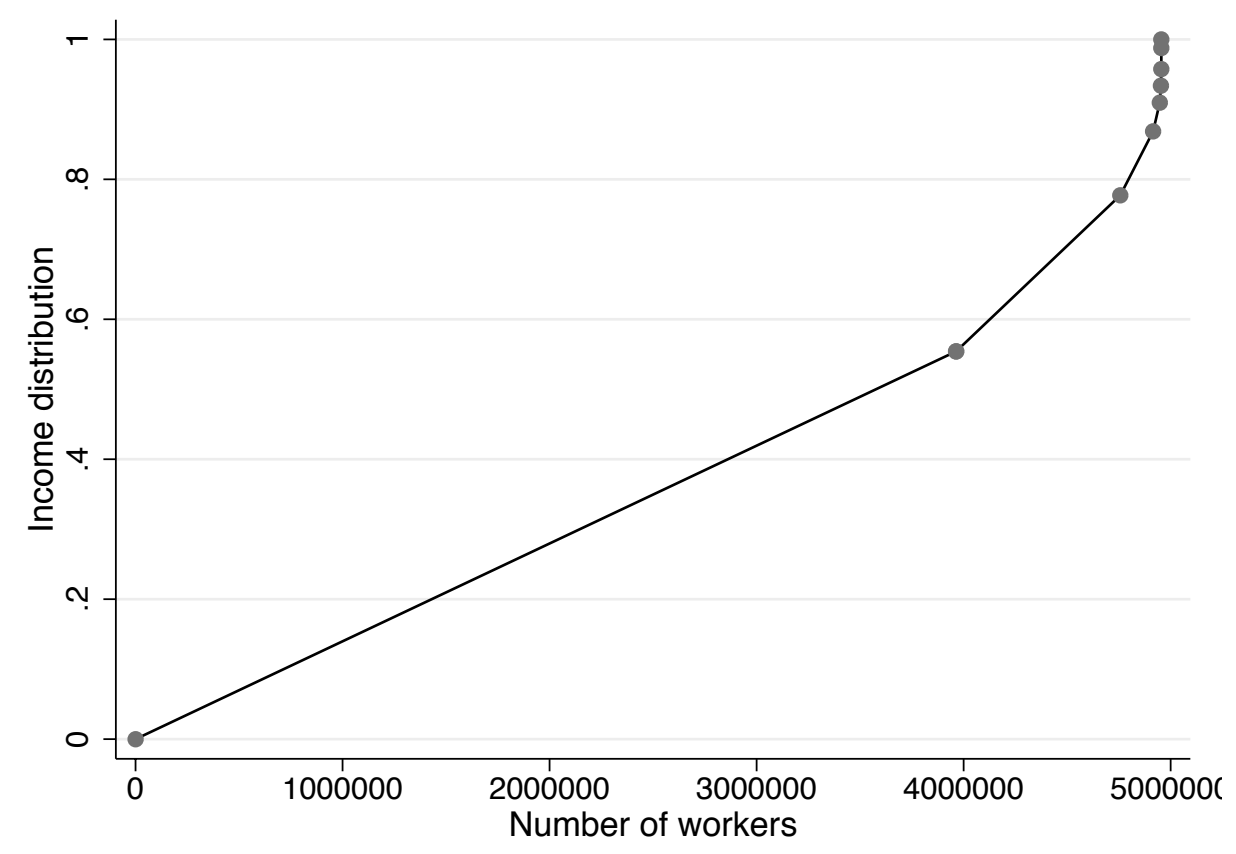

Figure 5: An approximation of the Lorenz curve: curve computed in the last time step of the simulation (2000) for one sample run. The straight connecting lines are an outcome of the assumption that individuals within a working class have the same income.

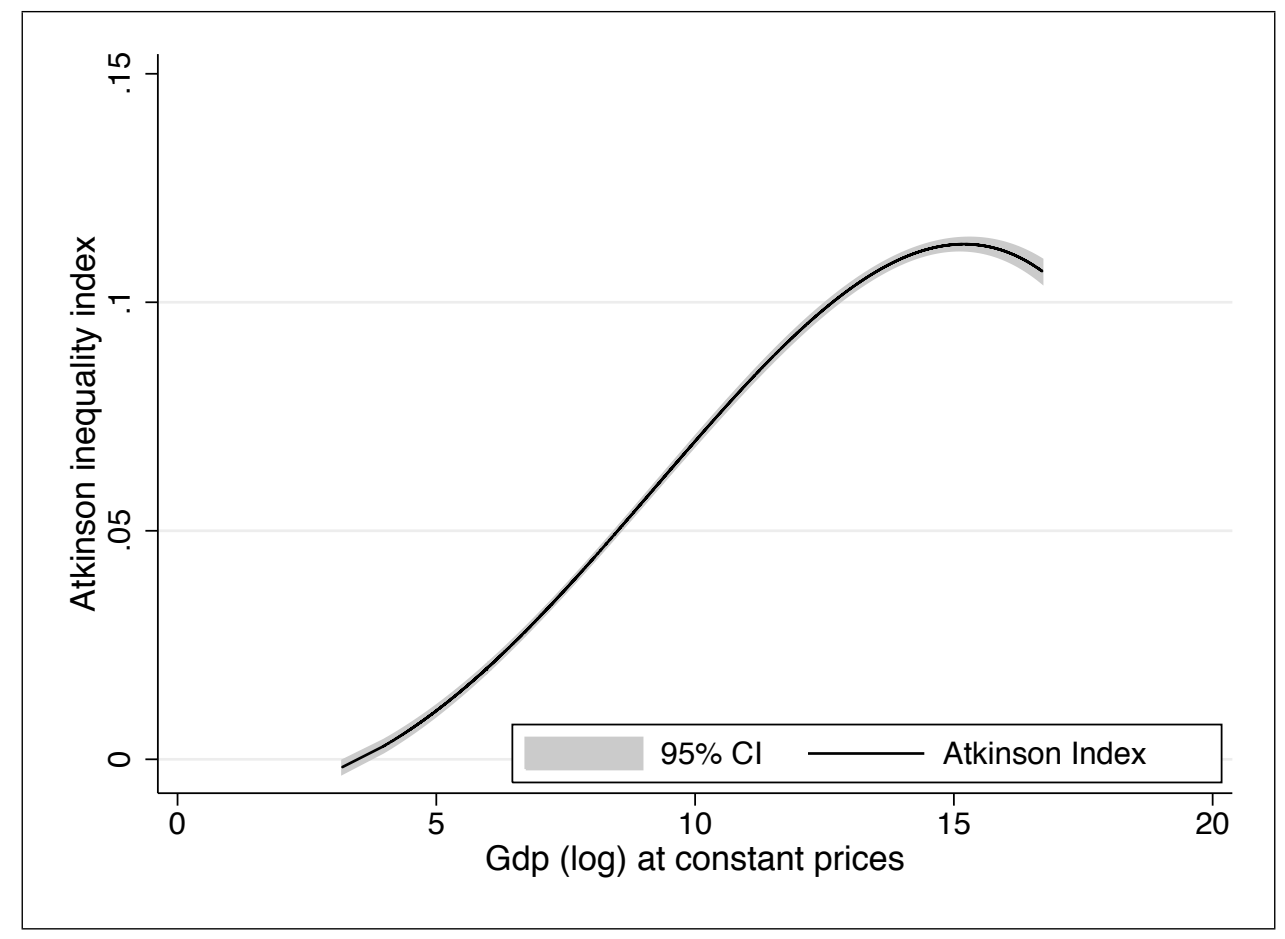

Figure 6: The relation between GDP and inequality. Levels of the inequality index vs levels of GDP, with the $95 \%$ confidence interval. 


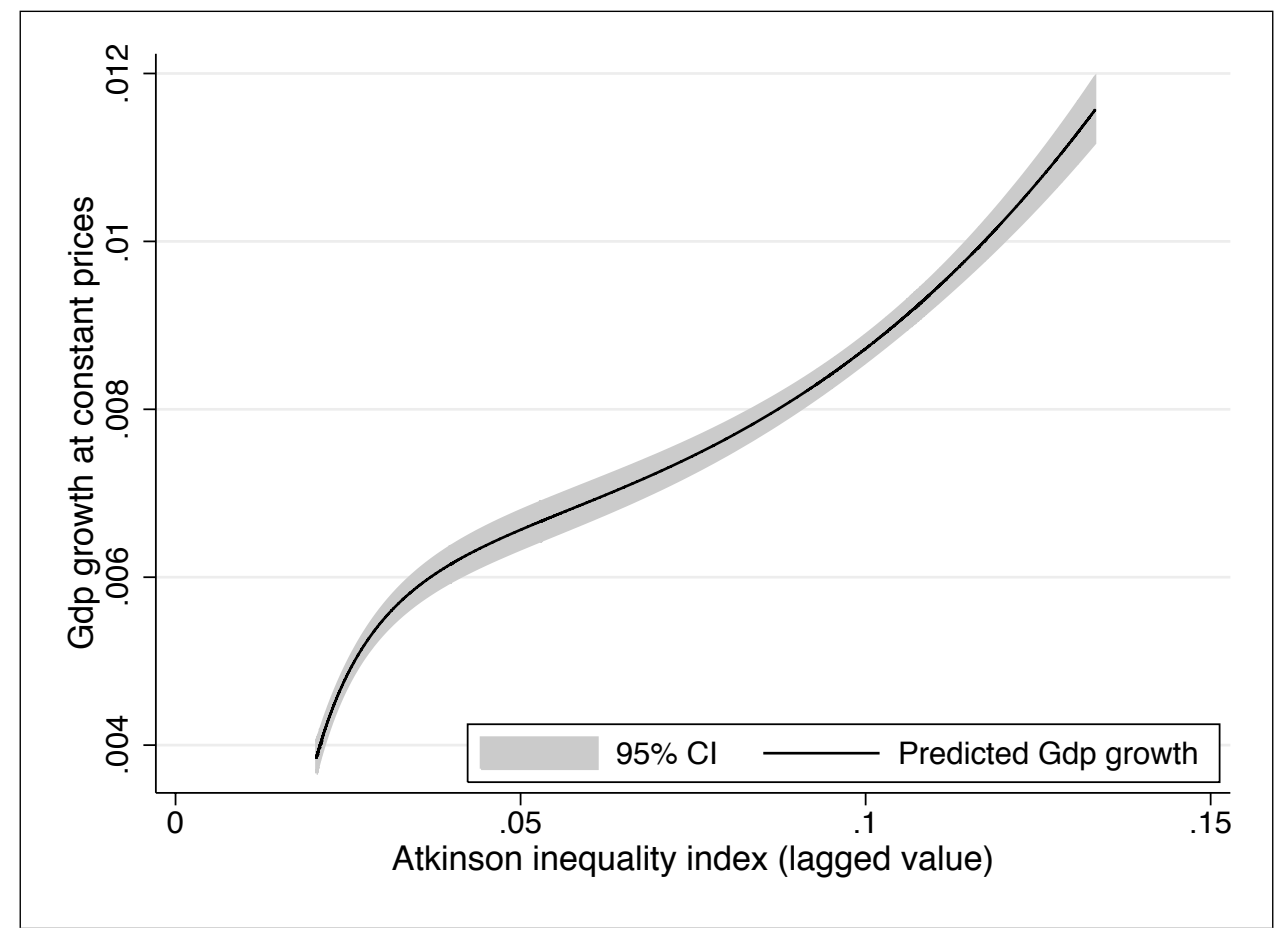

Figure 7: The relation between GDP and inequality. Levels of the inequality index vs. GDP growth, with the $95 \%$ confidence interval. 
Table 1: Parameters setting: initial values

\begin{tabular}{|l|l|c|}
\hline Par $/$ Var $_{t-1}$ & \multicolumn{1}{|c|}{ Description } & Value \\
\hline$W_{0}^{w}$ & Wage Income & 50 \\
$W_{0}^{\phi}$ & Profit Income & 100 \\
$w_{0}^{m}$ & Minimum wage & 1.25152 \\
$\bar{A}_{0}$ & Aggregate productivity & 0.18 \\
$\bar{p}_{0}$ & Average price & 1 \\
$\bar{A}_{0}$ & Moving average of aggregate productivity & 0.18 \\
$S_{0}$ & Firm stock & 0 \\
$Q_{0}$ & Firm production & 1 \\
$L_{0}$ & Work force & 5 \\
$p_{0}$ & Price & 0.2 \\
$Y_{0}^{e}$ & Expected sales & 1 \\
$c_{0}$ & Production cost & 125 \\
$A_{0}$ & Embodied labour productivity & 1 \\
$p_{0}^{k}$ & Capital firm price & 1 \\
$L_{0}^{k 1}$ & Capital firm work force & 1 \\
$z_{0}$ & Market shares & 0.02 \\
$a_{\tau_{0}}$ & Embodied labour productivity in capital vintage $\tau_{0}$ & 1 \\
\hline
\end{tabular}


Table 2: Parameters setting: parameter values

\begin{tabular}{|c|c|c|}
\hline Par/Var ${ }_{t-1}$ & Description & Value \\
\hline$a^{s}$ & Speed of adaptation of sales expectations & 0.9 \\
\hline $\bar{s}$ & Desired ratio of inventories & 0.1 \\
\hline$D$ & Capital coefficient & 0.4 \\
\hline$\epsilon_{L}$ & Labour market friction (final good firms) & 0.9 \\
\hline$u^{l}$ & Unused labour capacity & 0.05 \\
\hline$\nu$ & Tier multiplier & 5 \\
\hline$\omega$ & Minimum wage multiplier & 1.11141 \\
\hline$b$ & Executives wage multiplier & 2 \\
\hline$\mu$ & Markup & 0.2 \\
\hline$\delta$ & Capital depreciation & 0.001 \\
\hline$u$ & Unused capital capacity & 0.05 \\
\hline$\theta_{f}^{p}, \theta_{f}^{a}, \theta_{f}^{d}$ & Preference weights in capital supplier choice & $1,1,1$ \\
\hline$\epsilon_{M}$ & Labour market friction (capital firms) & 0.9 \\
\hline$u^{K}$ & Unused labour capacity in the capital sector & 0.2 \\
\hline$\omega^{K}$ & Wage multiplier in the capital sector & 1 \\
\hline$A^{K}$ & Labour productivity (capital firm) & 1 \\
\hline$\omega^{E}$ & Engineer's wage multiplier & 1.5 \\
\hline$\mu^{K}$ & Markup (capital firm) & 0.5 \\
\hline$\zeta$ & Parameter innovation probability & 10000 \\
\hline$\nu^{K}$ & targeted Worker-Engineer ratio (capital firm) & 5 \\
\hline$\rho$ & $\mathrm{R} \& \mathrm{D}$ investment share & 0.7 \\
\hline$\sigma^{a}$ & Standard deviation productivity shock & 0.01 \\
\hline$\epsilon^{U}$ & Wage curve unemployment elasticity & 0.1 \\
\hline$\epsilon^{A}$ & Wage curve productivity elasticity & 0.1 \\
\hline$\epsilon^{P}$ & Wage curve inflation elasticity & 0.5 \\
\hline$\Omega^{A}$ & $\begin{array}{l}\text { Increase in average productivity for a wage renegotia- } \\
\text { tion to occur }\end{array}$ & 0.05 \\
\hline$\Omega^{P}$ & $\begin{array}{l}\text { Increase in average price for a wage renegotiation to } \\
\text { occur }\end{array}$ & 0.05 \\
\hline$d$ & $\begin{array}{l}\text { Smoothing parameter in the computation of the mov- } \\
\text { ing averages }\end{array}$ & 0.05 \\
\hline$C^{H}$ & Beveridge curve constant & 0.2 \\
\hline$\beta$ & Beveridge curve parameter & 6 \\
\hline$\gamma$ & Smoothing parameter in consumers expenditures & 0.8 \\
\hline$H$ & Number of consumer class sub-groups & 50 \\
\hline$\sigma_{i}$ & Variance in the the evaluation of characteristics & $0.05 ; 0.1$ \\
\hline$\varsigma$ & Inter-class multiplier for tolerance levels & 0.2 \\
\hline$v_{1, q}$ & First income class tolerance towards quality & 0.1 \\
\hline$v_{1, p}$ & First income class tolerance towards price & 0.9 \\
\hline$v_{q}^{\max }$ & Maximum tolerance towards quality & 0.9 \\
\hline$v_{p}^{\min }$ & Minimum tolerance towards price & 0.1 \\
\hline$\varrho$ & Households' inequality aversion (Atkinson Index) & 0.5 \\
\hline
\end{tabular}

